\title{
1. Introduction on contracts and trust in alliances
}

Managers take one narrow perspective or another [. . .]. Much of this writing and advising has been decidedly dysfunctional, simply because managers have no choice but to cope with the entire beast. (Mintzberg and Lampel, 1999: 21)

Several competing lines of reasoning seem possible, although they might prove to be complementary rather than exclusive, since organizations are complex realities whose dynamics are 'overdetermined' and not typically amenable to a monocausal explanation. (Adler, 1993: 172)

The central aim of this book is to explore how contracts and trust relate to the discovery, creation and appropriation of value by partners in interorganizational relationships. This introductory chapter serves as a foundation for such a study. Here I briefly touch upon the growing prominence of interorganizational collaboration and the significance that is attributed to the governance of cooperative initiatives. I then argue that existing studies on interorganizational governance generally take one narrow perspective or another, neglecting the fact that managers have no choice but to cope with the entire 'beast', and ignoring the fact that most organizational phenomena are not amenable to monocausal explanations (see Adler, 1993; Mintzberg and Lampel, 1999). Moreover, I contend that these studies have been dominated for decades by theories that have assumed an almost paradigmatic status. The challenge lies in accommodating and cherishing these existing theories, while at the same time attending to and developing new ideas that could possibly result in scientific progression. I therefore introduce an integrative research framework, incorporating six research themes that promise to shed new light on the relations between contracts, trust and the discovery, creation and appropriation of value in interorganizational relationships. Subsequently, I discuss each of these themes and the associated research questions, as well as the empirical and methodological basis for the manuscript. The chapter concludes with an overview of the structure of the book. 


\section{INTERORGANIZATIONAL COOPERATION}

Drucker (1995) suggests that the greatest change in the way business is being conducted is the accelerating growth of relationships based on partnership instead of ownership. Grant and Baden-Fuller (2004: 61) even contend that 'one of the most important trends in industrial organization of the past quarter century has been the growth of collaboration between independent companies'. Several other researchers have advanced the argument that organizations are increasingly forming external collaborative relationships, which they define as voluntarily initiated, formal, cooperative agreements between two or more organizations that involve exchange, sharing, or co-development, and that include contributions by partners of capital, technology or organization-specific assets (e.g. Ariño, 2003; Gulati, 1998; Parkhe, 1993a).

Support for this assertion is ubiquitous. Kang and Sakai (2001), for example, observed that the number of interorganizational alliances was six times as high in 1999 compared to a decade earlier. The top 500 global businesses have been estimated to participate in an average of 60 major strategic alliances each (Dyer et al., 2001), while public reports indicate that BP Amoco, Dow Chemical, Hearst, Johnson \& Johnson and Sony had more than a hundred alliances in their corporate portfolios by 2001 (Bamford and Ernst, 2003). Large pharmaceutical companies and software firms constitute major examples of the hunger for interorganizational cooperation (see Table 1.1). From 2000 to 2003, the top 10 companies in the pharmaceutical industry had established, on average, 61 new alliances (Rasmussen, 2004).

\section{Table 1.1 Number of alliances, top 10 drug development companies (2000-2003)}

\begin{tabular}{lc}
\hline Company & \# of worldwide alliances \\
\hline Pfizer & 103 \\
GlaxoSmithKline & 88 \\
Merck & 62 \\
Aventis & 57 \\
Roche & 56 \\
Novartis & 56 \\
Eli Lilly & 51 \\
Bristol-Myers Squibb & 47 \\
Abbott & 45 \\
AstraZeneca & 44 \\
\hline
\end{tabular}

Source: Rasmussen (2004, based on Recap, March 2004). 
In a similar vein, Lavie (2007) observed that the percentage of publicly traded firms in the US software industry engaging in alliances increased from 32 per cent to 95 per cent between 1990 and 2001, with the average number of alliances in their portfolio rising from four to more than 30 (see Figure 1.1). Further evidence is derived from estimates by Goldman Sachs that a typical Fortune 1000 organization is currently maintaining between 20000 and 40000 contracts (upsidesoft.com, 2005) and from Schifrin's interviews among toplevel managers (2001), revealing that more than 80 per cent of them regarded strategic alliances as a primary growth vehicle for the future. Support also comes from the worldwide market for IT outsourcing, which has been forecast by Gartner to grow at an annual compound rate of 7.2 per cent between 2003 and 2008 (Caldwell et al., 2004). These examples suggest that interorganizational relationships have grown in volume and number and that we can expect this trend towards collaboration to continue.

These and other examples suggest that activities of organizations are increasingly embedded in complex networks of interorganizational relations and in constantly reconfiguring value chains (Wirtz, 2001). Changes in communication technologies and increasing openness of economies have amplified the potential value that may be created through interorganizational cooperation, permitting organizations to set up closer relationships with

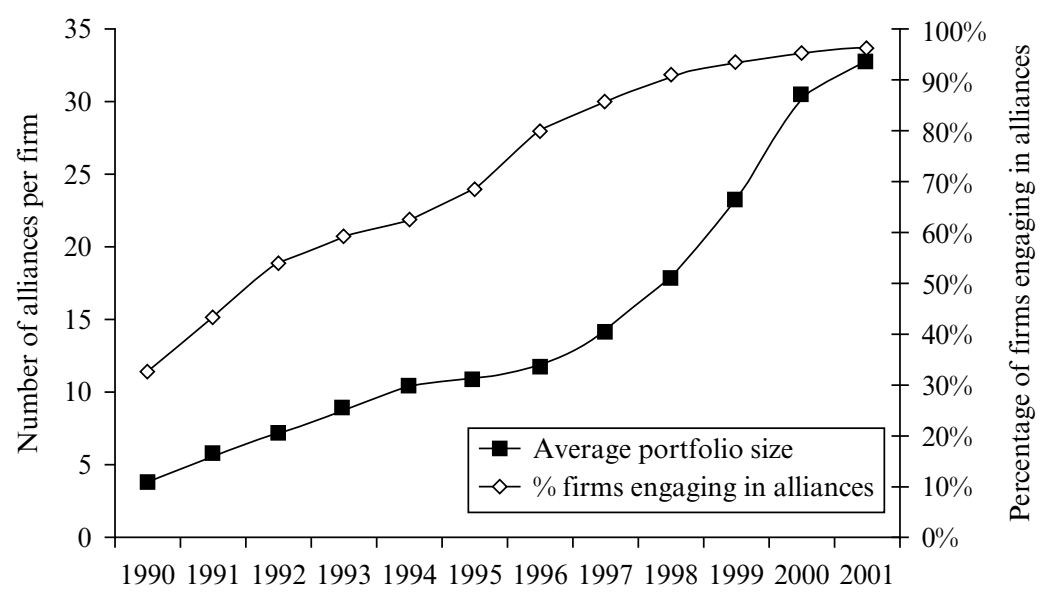

Year

Source: Lavie (2007). The figure presents the percentage of publicly traded firms in the US software industry that engage in alliances and their corresponding alliance portfolio size, measured in terms of number of alliances.

Figure 1.1 Evolution of alliance portfolios in the US software industry 


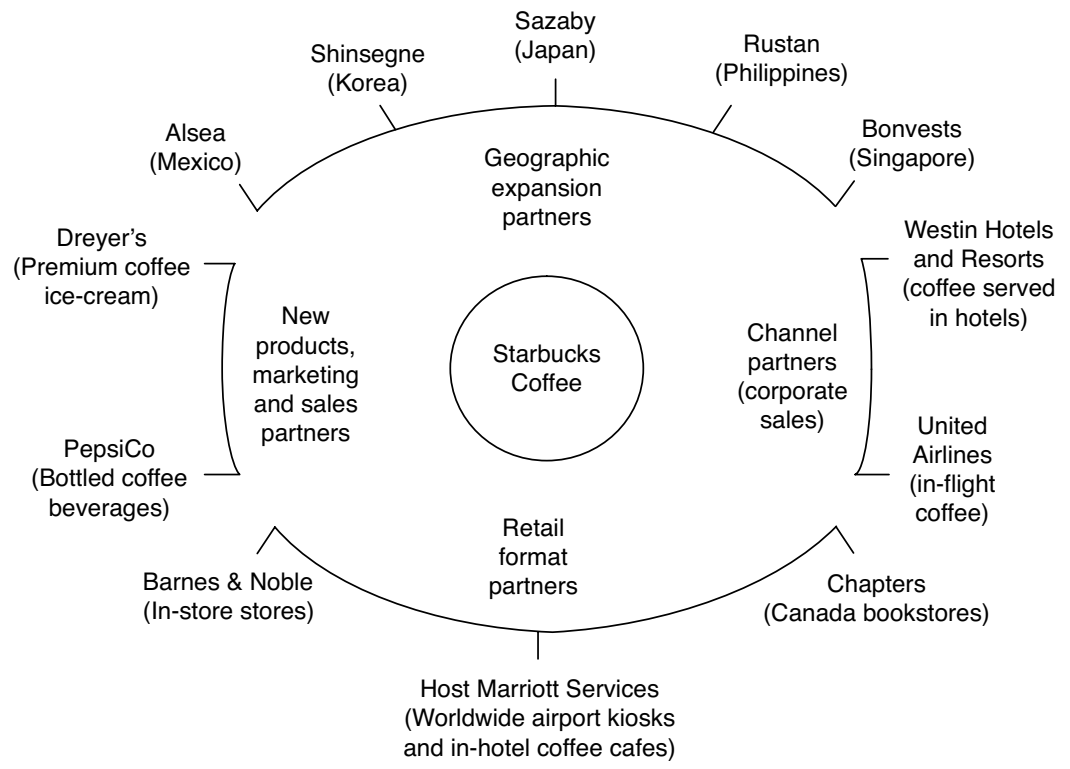

Source: Ernst (2003, based on press reports and McKinsey Analysis).

Figure 1.2 Starbuck's coffee creating value through a set of relationships

partners than hitherto possible (Mol, 2005). Take the example of Starbucks Coffee, which has leveraged a brand and a concept by means of a large set of interorganizational relationships (see Figure 1.2). Starbuck's partners include firms that facilitate entry into new markets; customers, including United Airlines and Westin Hotels; retail formats, such as Mariott, Barnes \& Noble and Chapters; and producers of complementary products, including PepsiCo and Dreyer's Ice Cream (see Ernst, 2003).

Another example constitutes Accenture (see Figure 1.3), which has developed relationships in the areas of application infrastructure, business intelligence, customer relationship management, data warehousing, enterprise integration and management, platforms and supply chain management. Nowadays, cooperation is even extended to strategically sensitive areas, such as R\&D. Boeing, for example, is working with India's HCL Technologies to co-develop software for everything from the navigation systems and landing gear to the cockpit controls for its upcoming 7E7 Dreamliner jet. Similarly, pharmaceutical giants such as GlaxoSmithKline and Eli Lilly are teaming up with Asian biotech research companies in a bid to cut the average $\$ 500$ million cost of bringing a new drug to the market (Engardio and Einhorn, 2005: 52-3). 

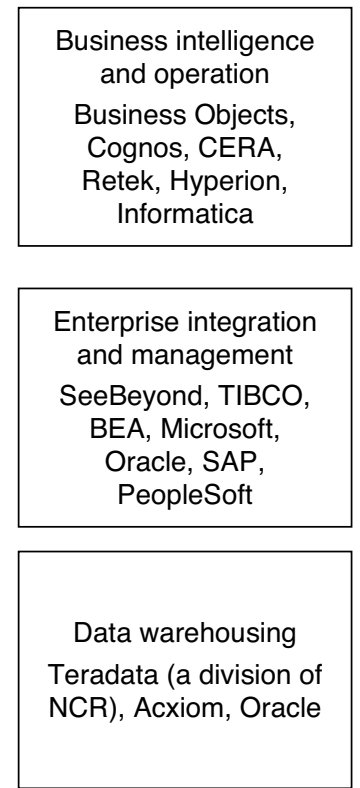
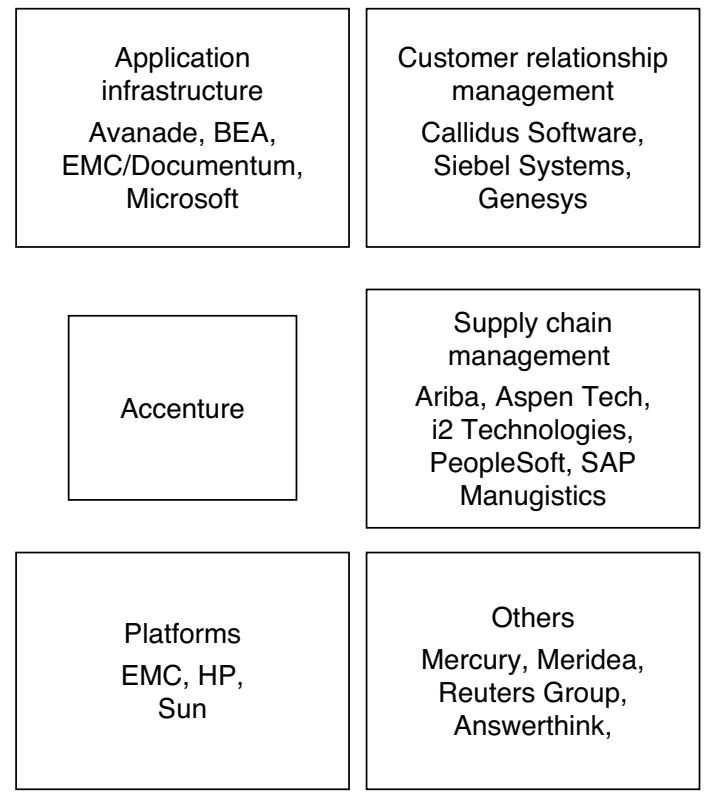

Source: Composed on the basis of data located at www.accenture.com.

Figure 1.3 Accenture creating value through a set of relationships

What drives these organizations to ally, sometimes even with their closest competitors? Lerpold (2003) and Ariño (2003) have composed excellent overviews of the motives for forming interorganizational relationships. These include reducing production and transaction costs (Hennart, 1988; Williamson, 1985), expanding business activities and exploiting business opportunities abroad (Mohr and Puck, 2005), accelerating the pace of organizational growth (Grant and Baden-Fuller, 2004; Shane, 1996; Uzzi, 1997), tapping resources for entrepreneurial activities (Teng, 2007) and accessing complementary resources and capabilities (Doz and Hamel, 1998; Dyer and Singh, 1998). In addition, interorganizational relationships are used to confer status, legitimacy and reputation on organizations (Baum and Oliver, 1992; Dacin et al., 2007; Stuart et al., 1999), augment their identity (Lerpold, 2003), enable conformance to isomorphic bandwagon behaviour (DiMaggio and Powell, 1983), increase market power through competitive positioning (Kogut, 1988) and enhance flexibility (Volberda, 1996, 1998; Schilling and Steensma, 2001). Collaboration among organizations is further driven by the need to respond to networks of competitors (Gimeno, 2004). In fact, competition frequently extends 
beyond rivalry between individual organizations (Ireland et al., 2002) and increasingly involves constellations of firms (Van Haverbeke and Noorderhaven, 2001) or cliques (Rowley et al., 2004). In a sense, interorganizational relationships thus create 'new forms of competition that supersede firms and on which firms depend for their competitive advantage' (Gomes-Casseres, 1996: 204). A good example consists of the battles among airline constellations Star and Oneworld in the early 2000s (Bamford et al., 2003).

External cooperative agreements also enable organizations to draw 'their boundaries around narrower spheres of activity' (Whittington et al., 1999: 587), allowing them to focus on their core competences (Prahalad and Hamel, 1990). They afford benefits, in the form of a larger volume, diversity and richness of information available to organizations (Koka and Prescott, 2002). This opens up possibilities to learn and access, transfer, transform and harvest knowledge (Beamish and Berdrow, 2003; Grant and Baden-Fuller, 2004) and it may reinforce the pace of innovation and reduce the risks associated with exploration (Sivadas and Dwyer, 2000). Moreover, it can give way to strategic renewal processes that enable organizations to pursue new developments in technologies, products and markets (Crossan and Berdrow, 2003; Lorenzoni and Lipparini, 1999; Volberda, 1996; Volberda et al., 2001). At the same time, collaboration tends to 'lower the costs of restructuring and transforming business by facilitating learning', and reducing the time that is needed to change (Gomes-Casseres, 1996: 45). Crossan and Berdrow (2003), for example, convincingly describe how Canada Post Cooperation transformed itself from a distribution company into a network management organization by outsourcing its retail activities. Furthermore, Lorenzoni and Lipparini (1999), in their study of supplier networks in the Italian packaging machine-building industry, illustrate that the ability of companies to interact with other organizations enabled them to renew their competences, while reducing resistance to change.

These and other examples show that achieving competitive advantage sometimes becomes inextricably linked to interorganizational cooperation (Dyer and Singh, 1998; Larson, 1992) and that the locus of production is often no longer within the boundaries of a single organization, but occurs instead at a nexus of relationships (Schilling and Steensma, 2001). In fact, 'the very unit of economic behaviour is becoming larger than the firm' (Gomes-Casseres, 1996: 5). Accordingly, we are challenged to complement the traditional picture of firm-driven production and growth with a view in which interorganizational relationships are used to organize economic activity and gain competitive advantage (Dyer and Singh, 1998; Koza and Lewin, 1998; Larson, 1992). This means that we need to replace traditional 
definitions of the field of strategic management focusing on 'coordination and resource allocation inside the firm' (Rumelt et al., 1991: 19) with definitions emphasizing 'coordination and resource allocation both within and across firm boundaries' (Madhok, 2002: 547).

\section{THE CRITICAL ROLE OF GOVERNANCE}

Thus far, I have concentrated on the virtues of interorganizational cooperation. ${ }^{1}$ However, interorganizational cooperation exhibits a 'mix of promise and peril' (Fryxell et al., 2002: 866). Although managers 'perceive the need for interorganizational cooperation, they find it difficult to manage those relationships satisfactorily' (Madhok, 1995: 57). ${ }^{2}$ This becomes manifest, for example, when one considers that alliance researchers have reported typical failure rates between 50 and 70 per cent (e.g. Harrigan, 1988; Heimeriks and Duysters, 2007; Parkhe, 1993a). It appears that many interorganizational relationships do not live up to their expectations (Hoang and Rothaermel, 2005). Problems arise, among others, from inherent conflict, goal divergence, asymmetrical objectives and opportunism by one or more partners (Doz, 1996; Ireland et al., 2002; Kale et al., 2000; Luo, 2007). Other issues pertain to cultural and organizational differences (Barkema and Vermeulen, 1997; Lane and Lubatkin, 1998; Mohr and Puck, 2005), improper partner selection (Ireland et al., 2002) and deficiencies or breaches of trust (Gill and Butler, 2003). These concerns are reinforced by variations in expectations regarding the possibilities for value creation and partner interaction (Inkpen and Beamish, 1997; Madhok and Tallman, 1998; Ring and Van de Ven, 1994). They are also exacerbated by unexpected contingencies, strategic changes by partner organizations and permutations in industries or environments, which may trigger instability (Gill and Butler, 2003; Yan and Gray, 2001), shifts from cooperative toward competitive behaviour and the dissolution of relationships.

Park and Ungson (2001) argue that the adaptation of appropriate governance mechanisms may alleviate or mitigate these and other potential problems, as governance mechanisms are means to infuse order, relieve conflict and realize mutual gain (Williamson, 2002). Contract design, for instance, 'can play an important role in facilitating joint problem-solving aimed at creating and preserving value' in interorganizational exchanges (Argyres and Mayer, 2007: 1061). This assertion receives support from, amongst others, a McKinsey study of more than 500 alliances involving large US, European, Asian and Latin American companies, revealing that many cooperative ventures fail because of unclear decision-making rights (Bamford et al., 2003). It is also empirically substantiated with results from 
a study on alliances in the drug industry conducted by Accenture (2003), indicating that interorganizational effectiveness frequently suffers from inadequacies in governance and relationship management. In line with this, Ernst (2003) concludes that about half of alliance failures result from governance issues and Madhok (2002: 540) adds that 'governance skills, both within and across firm boundaries, can result in performance differences and competitive advantage'.

Several other authors have also emphasized the significance of interorganizational governance. Dyer and Singh (1998), for instance, stress that effective governance might lead to interorganizational competitive advantage, either by lowering transaction costs or by providing incentives for partner organizations to pursue value creation initiatives, such as investing in relation-specific assets, sharing knowledge or combining complementary strategic resources. Bagley (2005), Ireland et al. (2002), Mayer and Argyres (2004) and Argyres and Mayer (2007) note that organizations possessing appropriate governance skills for managing and controlling interorganizational relationships extend their productive opportunity sets. Such organizations are able to address complementary resources and technologies from other organizations (Child and McGrath, 2001; Sanchez and Heene, 1997) and they may be in a better position to renew themselves, as their governance skills enable the internalization of cooperative experiences. In summary, the extent to which gains can be obtained from interorganizational collaboration appears to depend on the appropriate use of governance mechanisms (Sampson, 2004a; Mayer and Nickerson, 2005; Williamson, 2002).

Unfortunately, the issue of how to manage and govern external relationships in order to gain competitive advantage has remained unsolved (Takeishi, 2001). To improve managerial practices and enhance the performance of interorganizational relationships (Barringer and Harrison, 2000), we thus need to increase our understanding of the governance structures and processes that are used to design and manage interorganizational relationships, and we have to improve our comprehension of the forces shaping collaborative agreements (Olk and Elvira, 2001; Osborn and Hagedoorn, 1997). Table 1.2 provides an overview of comments issued by various authors indicating that governance mechanisms and processes constitute important determinants of interorganizational performance (e.g. Grandori and Soda, 1995; Masten and Saussier, 2002; Reuer, 1999; Sampson, 2004a; Zollo and Singh, 2004). Table 1.2 also includes calls for further investigating the skills, mechanisms and processes associated with the governance of interorganizational relationships (Colombo, 2003; Thatcher, 2004; Wright and Lockett, 2003) and it points at opportunities for making progress in this field (Anderson and Dekker, 2005; Shapira, 2000; Sobrero and 
Table 1.2 Significance of and criticism on interorganizational governance research

\begin{tabular}{ll}
\hline Authors & Citation \\
\hline $\begin{array}{l}\text { Masten and } \\
\text { Saussier }\end{array}$ & $\begin{array}{l}\text { 'The growth in the analysis of inter-firm contractual } \\
\text { relationships that has occurred in recent years is an indication of } \\
\text { the importance economists associate with the issue of contracting } \\
\text { and contract design' }\end{array}$ \\
$\begin{array}{l}\text { Grandori } \\
\text { and Soda }\end{array}$ & $\begin{array}{l}\text { to which inter-firm relationships are formalized [. . . ] is an } \\
\text { (1995: 198) }\end{array}$ \\
important dimension of inter-firm organizing'
\end{tabular}

Reuer '[Deriving value from alliances] . . . requires companies to select the

(1999: 13) right partners, develop a suitable alliance design, adapt the relationship as needed, and manage the end game appropriately'

Zollo and 'Generally, it might be possible to achieve synergy only when firms Singh carefully design and execute integration processes focused on (2004: 6) extracting the gains associated with the combination of the two organizations. Accordingly [. . .] it is important to include as explanatory variables the activities necessary to extract those rents'

Sampson 'One possible explanation for this performance difference across (2004a: 484) alliances is variation in alliance governance; specifically, whether alliance governance is appropriately chosen given the characteristics of the alliance'

Thatcher 'The growing enthusiasm for partnerships has created great (2004: 92) demand for the skills required to manage them as well as for scholarship that can shed light on what those skills might be'

Wright and Although examples of collaborative agreements are becoming Lockett increasingly common, our understanding of their operation and

(2003: 2074) management does not reflect their expanding role in economic activity'

Colombo 'More direct and fine-tuned consideration of the specific

(2003: 1226) coordination and control mechanisms incorporated in different alliances [. . . ] would be very useful to gain further insights'

Sobrero and 'A first reading of the empirical studies collected for the meta-

Schrader (1998: 601) analysis reveals the absence of an integrated perspective that simultaneously considers the relationships between task characteristics, the contractual and procedural dimensions of inter-firm relationships, and the outcome of the relation'

Shapira 'The next step should be a more comprehensive perspective on (2000: 64) governance. As Grandori (1997) suggested, it may be less fruitful to attempt to resolve past debates than it is to foster crosspollination among different perspectives' 
Table 1.2 (continued)

\begin{tabular}{ll}
\hline Authors & Citation \\
\hline Anderson & '. . . a great deal of work is needed to understand management \\
and Dekker & $\begin{array}{l}\text { control practices that are emerging at the blurry boundaries of } \\
\text { firms. This work [. . . ] requires the researcher to become } \\
\text { conversant in a broader body of business research' }\end{array}$ \\
\hline
\end{tabular}

Schrader, 1998). In particular, authors have noted that 'an integrated perspective that simultaneously considers the relationships between task characteristics, the contractual and procedural dimensions of inter-firm relationships, and the outcome of the relation' has remained absent (Sobrero and Schrader, 1998: 601; see also Faems et al., 2007). Others observe that 'the next step should be a more comprehensive perspective on governance', as 'it may be less fruitful to attempt to resolve past debates than it is to foster cross-pollination among different perspectives' (Shapira, 2000: 64). Anderson and Dekker (2005: 1751) explain that this 'requires the researcher to become conversant in a broader body of business research'. These comments indicate that a critical examination of the role of governance in interorganizational relationships is both timely and warranted.

However, such an endeavour is unlikely to be valuable in the absence of a clear focus. The number of governance mechanisms that one could consider is so large, and the types of governance decisions that one could take into account is so diverse, that including them all would only obfuscate our view and hamper progression. In exploring the role of governance in interorganizational relationships, I therefore focus particularly on two types of governance that have received considerable and growing attention in the literature over the last decades, being contracting and trust.

\section{DEFINITION AND TYPOLOGY OF CONTRACTING}

Parties in interorganizational relationships tend to 'regulate their future conduct [as well as inputs and outcomes] ex ante by means of mutual forbearance and more or less formally specified contractual mechanisms' (Dacin et al., 2007: 170). In fact, contracting constitutes a principal means of formalization in interorganizational relationships. A comprehensive definition of contracting therefore necessitates a closer look at formalization. Most concepts ending in '-tion' are ambiguous with regard to process and outcome: 'between the way one gets there, and the result' (Baum and Rowley, 2002: 1). This also accounts for formalization, which refers both to 
the process of negotiating, codifying and enforcing inputs, outputs and behaviours (Ouchi and Maguire, 1975; Ouchi, 1979), and to the outcomes of this process in the form of contracts, ${ }^{3}$ rules and procedures (Aiken and Hage, 1966). The same distinction holds for contracting, which consists both of a 'process of projecting exchanges into the future' (Macneil, 1980: 4 , italics added) and of the actual promises or obligations to perform particular actions in the future, which may be recorded in formal contracts, being the outcome of negotiation and contracting processes (Macneil, 1980). My ontological view of contracting covers both contracting processes (i.e. negotiation, codification and enforcement) as well as contractual structures (i.e. clauses and terms). I focus as much on the contracting process - involving things such as defining partners' performance, duties and rights in future circumstances; defining what should happen when parties do not hold to agreements; and assessing to what extent the contract can be legally enforced (Luo, 2007; Macaulay, 1963) - as on the contractual structures in which they eventuate, because I believe that contracting 'accomplishes part of its purpose not just with the words agreed upon', but also by means of the process through which parties arrive at these words, and through the 'words discussed and ultimately rejected' (Hill, 2001a: 56).

Next to a definition, I develop a typology of contracting based on three of its main attributes (see Figure 1.4). The first and most commonly discussed attribute refers to the degree to which inputs, behaviour and outcomes are codified and enforced, which may range from low to high (Faems et al., 2007; Luo, 2007). Before I proceed, let me explain what is meant by codification and enforcement. Codification conveys that explicit, systematic procedures are involved (Pearce et al., 1987), which help to create perceptual and conceptual categories that facilitate the classification of phenomena (Boisot, 1998). It refers to explicitly recording or writing down aspects of inputs, outcomes and/or behaviour. Enforcement, instead, signifies that codified agreements are 'in force'. It permits parties to make believable promises to each other, so that the execution of agreements can ultimately be exacted (Luo, 2007; Schwartz and Scott, 2003). ${ }^{4}$ Enforcement does not necessarily mean that partner organizations are 'forced to comply'; it implies that they act with the negotiation and contracting process and its outcomes in mind. Enforcement seldom takes place by actually appealing to courts or authority. ${ }^{5}$ Instead, the sheer existence of sources for ultimate appeal (Galanter, 1981; Salbu, 1997; Williamson, 1999), ${ }^{6}$ the wish to avoid ruining relationships and reputations, and considerations related to cost efficiency are generally sufficient to guarantee compliance by partner organizations (Antia and Frazier, 2001; Elfenbein and Lerner, 2003; Klein, 2002; Lazzarini et al., 2007). Moreover, contracts may be in force just 


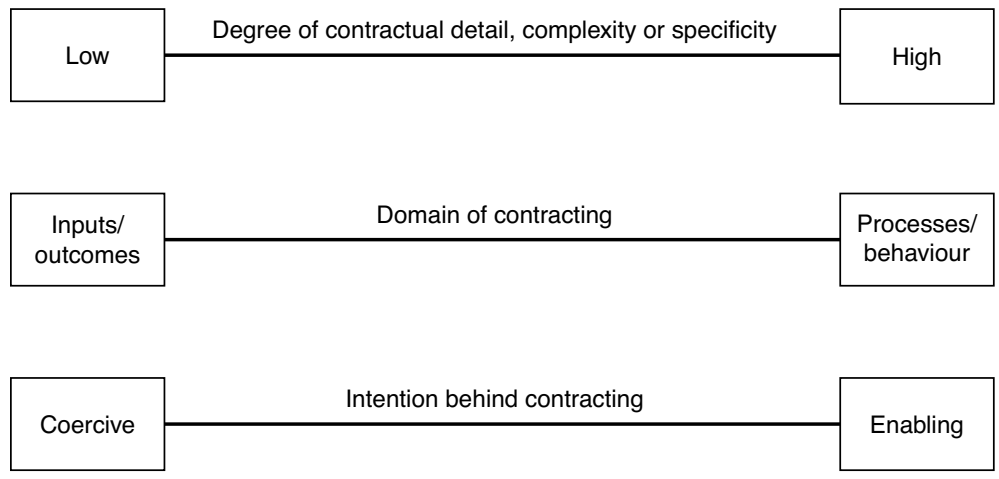

Figure 1.4 Three attributes of contracting

because partners are highly dependent on each other (Blois, 1972; Lazzarini et al., 2007; Richardson, 1972; Telser, 1980; Zollo et al., 2002). In these cases, 'formalization into contracts is redundant because interests are convergent' (Grandori, 2006: 129).

As has been mentioned before, the attribute of contracting that is most commonly used by researchers concerns the degree of detail, specificity or complexity of contracts (e.g. see Anderson and Dekker, 2005; Barthélemy and Quélin, 2006; Makhija and Ganesh, 1997) and the length and intensity of negotiation and contracting processes associated with it. Variation on this dimension may stem, amongst others, from the prohibitively high costs involved with specifying, monitoring and enforcing all elements of economic performance for a wide range of possible contingencies. As a result, contracts are necessarily incomplete (Grossman and Hart, 1986) and parties are encouraged to align degrees of contractual detail, complexity or specificity with organizational, exchange and contextual characteristics (Williamson, 1991, 1996, 1999). It may also stem from differences in relative bargaining power, with lower bargaining power reducing a focal party's ability to include specifications in the contract (Faems et al., 2007). A second attribute pertains to the domain of contracting, which may involve either the inputs and outcomes of a relationship or the behaviour of the contracting parties and the processes that take place during the course of the relationship (e.g. see Grandori and Furlotti, 2007; Koza and Lewin, 1998; Ouchi, 1979; Ouchi and Maguire, 1975; Schwartz, 2004; Stinchcombe, 2001). This distinction derives from the work of Katz and Kahn (1966), Simon (1947/1997) and Stinchcombe (2001), who have examined these concepts on an intraorganizational level. Katz and Kahn (1966: 298), for example, propose two major categories of policy making: 'the formulation of organizational goals and objectives, and the formulation of 
strategies and procedures for achieving and assessing progress towards such goals'. In a similar vein, Simon (1997: 307) contends that someone 'may be told what to do, but given considerable leeway as to how [he or she] will carry out the task'. Stinchcombe (2001: 51) refers to this distinction by stating that 'abstract versions of procedures and technologies may be formulated in terms of their outcomes [. . .], or by the sequence of actions that are thought to reliably produce the best results'.

Contracting of the expected outcomes of a relationship concerns the delineation of goals and the scope of a relationship (Cyert and March, 1963; Cheng and Van de Ven, 1996; Oxley and Sampson, 2004). It entails the inclination, determinedness and means to be able to hold on to this scope and work according to the goals set earlier on (McGrath, 2001). Contracting of inputs and outcomes further refers to the codification and enforcement of what is to be accomplished (e.g. scope, goals), and by what means this has to be done. Contracting of processes and behaviours, instead, entails the coordination and adjustment of activities of interdependent parties (Sobrero and Schrader, 1998). It encompasses the specification and supervision of operational or post-formation activities (McGrath, 2001), so that control can be exerted over these (Burns and Stalker, 1961). When contracting pertains to processes and behaviour, contracts specify, for example, terms and clauses concerning how to set up the relationship, how to operate and manage the relationship, and how to cooperate and resolve conflict between partners (Luo, 2002). In this case, contracting refers to the codification and enforcement of how outcomes are to be realized. ${ }^{7}$ The resulting contracts contain series of clauses linking combinations of various possible elementary events to prescriptions of behaviour or elementary actions (Schwartz, 2004). The difference between contractual clauses pertaining to inputs and outcomes and contractual terms specifying behaviours and processes is illustrated here with an example of a contract aimed at the development of a custom-made printhead in an R\&D alliance between an imaging company (GRAPH) and an inkjet technology firm (JET), as discussed by Faems et al. (2007: 24-5).

[A]part from programme milestones, target dates, and performance standards that formalized JET's expected outputs (i.e. delivery of the printheads), the ESH contract also contained contractual statements regulating the activities that JET was supposed to conduct in order to meet these milestones. For instance, it was stipulated that, during the first six months of the ESH alliance, JET had to execute the following activities: 'allocate resources to the programme and establish working practices ... Define the detailed printhead specification required by GRAPH ... At the end of this stage the [JET] development team will produce a recommendation for the printhead design, and plans and detailed financial estimates for the remainder of the development programme through to full production'. (ESH Agreement Annex 1: Project Description ESH) 
Faems et al. (2007: 25) conclude that 'In this way, GRAPH could not only monitor the outputs of JET's activities but could also follow up the activities that JET had to conduct in order to arrive at these outputs.'

Finally, a third attribute of contracting refers to the intentions underlying contracting practices (Chaserant, 2003). In this respect, Adler (1993: 165) has noted that 'subsequent generations of researchers have tended to focus on the punishment-centred form and the associated compliance logic of bureaucracy' and the processes associated with it, such as contracting. In a study on the formalization of workflows in an intraorganizational context, Adler and Borys (1996) take issue with this observation and they distinguish enabling types of formalization, designed to enable employees or partner organizations to master their tasks, from coercive types of formalization, aimed at coercing effort, forcing reluctant compliance and displacing opportunism. ${ }^{8}$ The purpose of the enabling type of formalization is to achieve 'coordination and higher levels of understanding' (Zollo and Singh, 2004: 16) and to motivate participants in interorganizational relationships by other means than offering extrinsic rewards (Lindenberg, 2003). In contrast to coercive types of formalization, the focus is no longer on 'the sanctioning of modes of social conduct', but on 'the constitution of meaning' (Giddens, 1984: 18). ${ }^{9}$ In line with this dichotomy, I distinguish coercive from enabling types of contracting, and I suggest that the effectiveness of negotiation and contracting processes as well as their outcomes - contract clauses and terms - may vary owing to the manner in which they are initiated, whether by imposition or agreement. A description of two subsequent $R \& D$ alliances between an imaging company (GRAPH) and an inkjet technology firm (JET) provided by Faems et al. (2007) offers a neat illustration here. In the first alliance, GRAPH's managers saw that things went wrong, but they were contractually forced to stay on the sidelines. As a comment of one of GRAPH managers illustrates, the contract for the second alliance was therefore designed to reduce control by JET regarding the sharing of proprietary knowledge (Faems et al., 2007: 25):

From the SSH project we had learned that the ESH project should be defined in an alternative way. Therefore, the ESH project was initiated from another perspective. Now, GRAPH wanted to know more details and wanted to understand why some processes had a low yield.

\section{DEFINITION AND TYPOLOGY OF TRUST}

Trust features as the second major construct in this book. Rousseau et al. (1998: 395) define trust as 'a psychological state comprising the intention 
to accept vulnerability based upon positive expectations of the intentions or behaviour of another'. Their definition implies that trust involves choice (Luhmann, 1988) and the existence of risk (Mayer et al., 1995). Nooteboom also explicitly addresses these points in his definition of trust, stating that it 'entails that one does not expect to be harmed by a partner even though she has both the opportunity and the incentive to be opportunistic' (1999: 203). His definition indicates that trust consists of a subjective state of positive expectations (Das and Teng, 2001) and that the partner and its behaviour are the objects of trust (Inkpen and Currall, 2004).

In an attempt to distinguish the different components of trust, Zaheer et al. (1998: 143) define trust as an exchange partner's expectation that the other party can be relied on, will behave as predicted, and will act fairly. This definition emphasizes the reliability, predictability and fairness as focal components of trust (Poppo et al., 2008), which coincide with the three 'factors of trustworthiness', being ability, benevolence and integrity. Ability concerns the context-specific skills and competencies that enable one to trust another to fulfil a given task. Benevolence regards the extent to which one is believed as wanting to do 'good'. Finally, integrity relates to one's willingness to follow mutually acceptable principles (Mesquita, 2007: 73). Trust thus not only encompasses the belief in the ability of a partner organization to accomplish a task, but also the belief in the goodwill or positive intentions of this partner, and the perception that it adheres to acceptable values (Mayer et al., 1995; Serva et al., 2005). Such expectations are confirmed 'when parties (1) demonstrate reliability by carrying out their promises, (2) act fairly when dealing with each other, and (3) exhibit goodwill when unforeseen contingencies arise' (Krishnan et al., 2006: 895). They are further reinforced and supported through the 'socialpsychological bonds of norms, sentiments and friendships' as well as the faith in the morality and goodwill of others (Ring and Van de Ven, 1994: 93; Uzzi, 1997). In line with the aforementioned, I follow Mayer et al. (1995: 712) in defining trust as 'the willingness of a party to be vulnerable to the actions of another party based on the expectation that the other will perform a particular action important to the trustor, irrespective of the ability to monitor or control that other party'. Moreover, I recognize that individual managers and not organizations as a whole trust their partners (Dodgson, 1993; Zaheer et al., 1998). I therefore refer to interorganizational trust and not interpersonal trust, or 'the extent of trust placed in the partner organization by the members of a focal organization' (Zaheer et al., 1998: 142).

Trust is frequently argued to develop from prior interactions. It is important to note, however, that trust does not only have its origins in the shadow of the past, but also in the shadow of the future. In fact, Poppo et al. (2008) 
advance and empirically substantiate that both aspects are strongly intertwined, having a synergistic effect on trust building. They contend that 'the past represents exchanges that have developed strong social institutions that support the development of trust-yet, without a shadow of the future, an end game looms large on the horizon and parties deviate from the prevailing norms and routines in order to maximize self-interest' (Poppo et al., 2008: 3). Poppo et al. (2008: 7) advance the point of view that expectations of continuity mediate the relationship between experience and trust, which 'is based on the logic that prior history generates learning of a non-trivial degree, which increases perceptions of stability and thus continuity of the interorganizational exchanges' from which trust emerges. In contrast, even when continuity is expected, without a long history the requisite social institution is relatively weaker and underdeveloped, leading to low levels of trust' (Poppo et al., 2008: 3). At the same time, past experience also moderates the relationship between expectations of continuity and trust, as developing trust is only sensible when continuity is required or desired. ${ }^{10}$ After all, a longer shadow of the future leaves more opportunities to profit from the shadow of the past (Poppo et al., 2008). In fact, without it, exchanges revert to the classic market 'atomistic' transaction (Macneil, 1980: 854). In this case, contracts gain in significance, at the cost of trust and other forms of relational governance (Lazzarini et al., 2007).

\section{INTERORGANIZATIONAL PERFORMANCE}

Next to contracting and trust, interorganizational performance concerns a third major construct in this study. Unfortunately, a precise and consistent definition of collaborative success and failure is still lacking in the literature, the diversity of measures that have been used is high and consensus on measuring the construct does not yet exist (Krishnan et al., 2006; Mohr and Puck, 2005; Sarkar et al., 2006; Yan and Gray, 2001). Researchers have tried to make sense out of the breadth of performance measures available, in several ways. Some authors have developed conceptual frameworks for organizing the available approaches to interorganizational performance measurement (e.g. Gray, 2000; Olk, 2002; Park and Ungson, 2001). ${ }^{11}$ Others have empirically evaluated the compatibility of various measures (e.g. Ariño, 2003; Geringer and Hébert, 1991; Glaister and Buckley, 1998; Hagedoorn and Cloodt, 2003). Finally, authors have argued that different contexts and research questions call for distinct performance measures (e.g. Gulati and Zajac, 2000; Reuer and Koza, 2000; Yan and Gray, 1995).

These performance measures all appear to have their own problems. Relationship mortality, for example, does not account for the fact that 
termination may indicate that partner organizations have attained their strategic objectives, or that they exit a relationship in a better competitive shape (Das and Teng, 2000; Gulati, 1998). It also does not consider the fact that organizations could pursue an options strategy to accomplish their objectives, developing large portfolios of relationships from which only one or a few need to be successful to prosper (Vassolo et al., 2004). In such cases, termination of a relationship may hinge on the comparative benefits generated in other initiatives. Moreover, it does not make allowances for gradations of performance (Gulati, 1998), although 'it is only realistic to expect alliances to fail in some respects (e.g. attaining original purposes) and to succeed in others (e.g. generating spin-offs)' (De Rond, 2003: 9). In addition, continuation of a relationship is not always in the partner's best interest (Reuer and Koza, 2000), as becomes apparent from a comment issued by the divisional president of a US firm, who ended a long-standing joint venture with a Japanese firm. He indicated that 'although the partnership was sound and the alliance had been very successful, the alliance no longer fits with firm strategy' (Inkpen and Li, 1999: 35). ${ }^{12}$

A more general problem with many performance measures is their focus on outcomes of relationships. Lately, several researchers have stressed that new insights may emerge by shifting the focus from solely measuring outcome performance to a view in which process performance measures are included (Ariño, 2003; Kumar and Nti, 1998). These measures can capture the fact that participants in interorganizational relationships might simply appreciate collateral experiences such as a bold move or a good meeting (March, 1999), and they could account for the fact that participants do not only judge results, but also the intentions behind the behaviour of others (Chaserant, 2003) and the extent to which they are satisfied with the patterns of interaction with their partner (Kumar and Nti, 1998). Support for the significance of process performance is afforded by De Rond (2003), who found that assessments of interorganizational performance and success in two alliances between pharmaceutical and biotechnology firms were based not solely, or even primarily, on economic or strategic considerations, but rather on cognitive processes of individuals in these alliances. A definition of interorganizational performance should therefore capture both outcome and process performance. Outcome performance then captures the effectiveness and efficiency of a relationship, including the degree of overall performance satisfaction, the presence of net spillover effects, the extent to which strategic goals are fulfilled, and parties' adherence to schedules and budgets (see Ariño, 2003; Hoang and Rothaermel, 2005; Mayer, 2006). Process performance, instead, pertains to the relational quality of cooperative endeavours (Ariño, 2003). It entails things such as the ease or smoothness of cooperation (Luo, 2002), the extent to which conflicts 
prevail in the relationship, and partners' satisfaction with coordination and communication processes (Poppo and Zenger, 2002).

Outcome performance and process performance have been argued to influence each other (Kumar and Nti, 1998; Zajac and Olsen, 1993) or to be inseparable (Parkhe, 1993b). Researchers have suggested, for example, that 'the pattern and quality of interaction between partners throughout the life of the [alliance] relationship determines the value created' (Madhok and Tallman, 1998: 333). Findings from Ariño (2003) and Hagedoorn and Cloodt (2003) support this assertion, suggesting that managers may need no complex metrics to evaluate interorganizational performance, as these measures are highly correlated. Accordingly, I refer to both processes and outcomes when discussing interorganizational performance in this study and I define interorganizational performance as 'the degree of accomplishment of the partners' goals [. . .], and the extent to which their pattern of interactions is acceptable to the partners' (Ariño, 2003: 23).

Evidence on the relationship between contracting, trust and interorganizational performance is mixed and narrow (Jap and Ganesan, 2000; Mayer and Nickerson, 2005; Poppo and Zenger, 2002; Sampson, 2004a; Sobrero and Schrader, 1998), something which might stem from the fact that different performance measures are being used in different analyses (Sobrero and Roberts, 2001, 2002). Moreover, the majority of these studies does not take into account the fact that firms arrive at their governance solutions purposefully, as opposed to randomly (Hamilton and Nickerson, 2003: 520; for exceptions, see Geyskens et al., 2006; Mayer and Nickerson, 2005; Rooks et al., 2006; Sampson, 2007). The most one can say is that the relationships between contracting and interorganizational performance is likely to follow a curve-linear path, where too little contracting gives rise to chaos and destructive or opportunistic behaviour and where too much contracting causes rigidity and curbs creativeness and entrepreneurial activities (Foss et al., 2007; Luo, 2002; Mintzberg, 1994; Sampson, 2004a). ${ }^{13}$ In this respect, Mintzberg (1994: 386) notes that 'formalization is a double-edged sword, easily reaching the point where help becomes hindrance'. The same accounts for the relationship between trust and interorganizational performance (see also Chapter 4), where very low levels of trust lead to suspicion and very high levels of trust entail naïveté.

Establishing unequivocal relationships between contracting, trust and interorganizational performance is not an easy task, since these relationships may be contingent on the stage of development (Jap and Ganesan, 2000), the type of relationship and the collaborative context in which it is embedded (Oxley, 1997; Sampson, 2003). They may also vary with the domains (inputs, outcomes, processes or behaviour) to which trust and contracting pertain (Ouchi and Maguire, 1975; Ouchi, 1979, 1980), and 
with the aims that managers have in mind when deciding on the governance of their relationships (Adler and Borys, 1996; Madhok, 2002). In addition, trust and contracting may have distinct effects on a range of performance measures (Sobrero and Roberts, 2001, 2002) and other governance forms may moderate these effects. Finally, trust and contracting are only two of the variables among a myriad of factors and processes affecting interorganizational performance (Beamish and Berdrow, 2003).

\section{NEED FOR AN INTEGRATIVE PERSPECTIVE ON INTERORGANIZATIONAL GOVERNANCE}

To summarize the discussion thus far, I have advanced that there is a paramount need for a more integrative perspective on interorganizational governance, while any effort at developing such a perspective should at least focus on a limited number of governance mechanisms so as to minimize possible confusion and indeterminacy. I then suggested that, throughout recent decades, contracting and trust have emerged as crucial aspects of interorganizational governance, which leads to a more refined research question: what role do contracts and trust play in interorganizational relationships?

To explore this issue, I build on the two main theoretical perspectives currently prevailing in the literature, which tend to focus either on the control or on the coordination function of interorganizational governance (Foss and Foss, 2005; Gulati and Singh, 1998; Madhok, 2002; Salbu, 1997). I contend that contributions to this literature typically inquire into the relationship between various governance mechanisms or processes and its antecedents, or into their relationship with performance (e.g. see Anderson and Dekker, 2005; Leiblein, 2003; Mayer and Nickerson, 2005; Poppo and Zenger, 2002; Sampson, 2004a; Sobrero and Schrader, 1998; Stinchcombe, 2001). The first group of inquiries presumes that antecedents of governance mechanisms and processes, such as complexity, asset-specificity or measurability are associated with the need or the ability to coordinate and control interorganizational behaviour and outcomes (e.g. Barthélemy and Quélin, 2006; Carson et al., 2006; Gerwin, 2004; Geyskens et al., 2006; Helm and Kloyer, 2004; Luo, 2002; Reuer and Ariño, 2007). The second category of studies focuses on the relationship between governance and interorganizational performance (e.g. Sobrero and Schrader, 1998; Mayer and Nickerson, 2005; Poppo and Zenger, 2002; Rooks et al., 2006; Sampson, 2004a, 2007). ${ }^{14}$ I capture these generic approaches to the research problem in what I call the 'antecedents-governance-performance model'. A visual representation of this framework is depicted in Figure 1.5. 


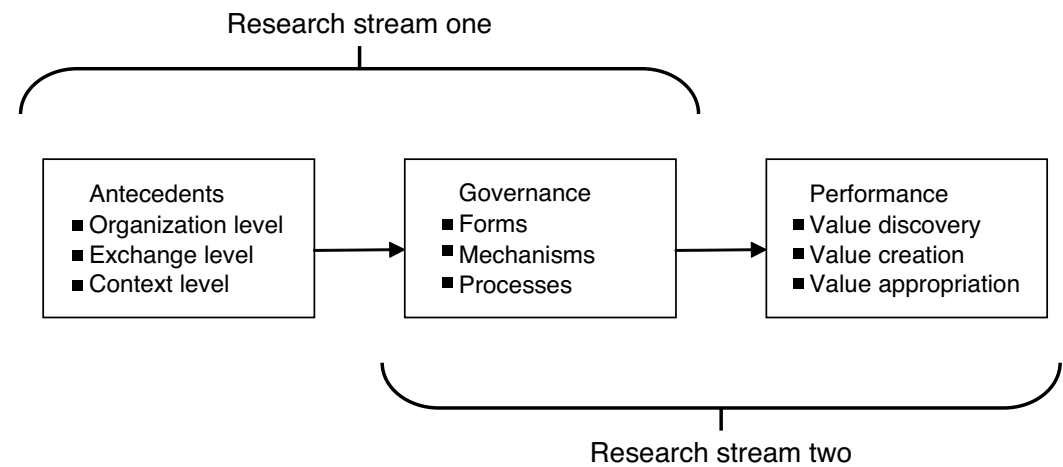

Source: Adapted from Vlaar et al. (2007).

Figure 1.5 Antecedents-governance-performance framework

Although the richness and variety of previous studies focusing on the antecedents-governance-performance framework have significantly contributed to our understanding, an integrative perspective on the role of contracts and trust in interorganizational relationships has remained absent in the literature thus far (e.g. Faems et al., 2007; Foss, 1999; Leiblein, 2003; Sobrero and Schrader, 1998; Stinchcombe, 2001). Similar to research on interorganizational collaboration in general (Oliver and Ebers, 1998), studies on interorganizational governance have built upon a cacophony of seemingly heterogeneous concepts, theories and research results, which generally prohibits a clear accumulation of knowledge and conceptual consolidation. In order to establish a less fragmented, disjointed and myopic perspective (Bell et al., 2006; Oliver and Ebers, 1998), throughout the manuscript I develop an integrative research framework, which is depicted in Figure 1.6. The framework illustrates that contracting and trust are affected by organization-, exchange- and context-level antecedents. These antecedents may influence the ability as well as the need to write and apply contracts and to trust a partner. Moreover, the framework shows that contracting and trust affect performance, as both governance mechanisms exhibit positive as well as negative consequences, or functions and dysfunctions. Finally, yet importantly, the framework suggests that performance effects of contracting and trust can be categorized in terms of value creation and value appropriation - constructs that are common to the literature - as well as value discovery. Although the discovery of value has received little attention in research on interorganizational governance, it assumes a central position in the remainder of this book. 


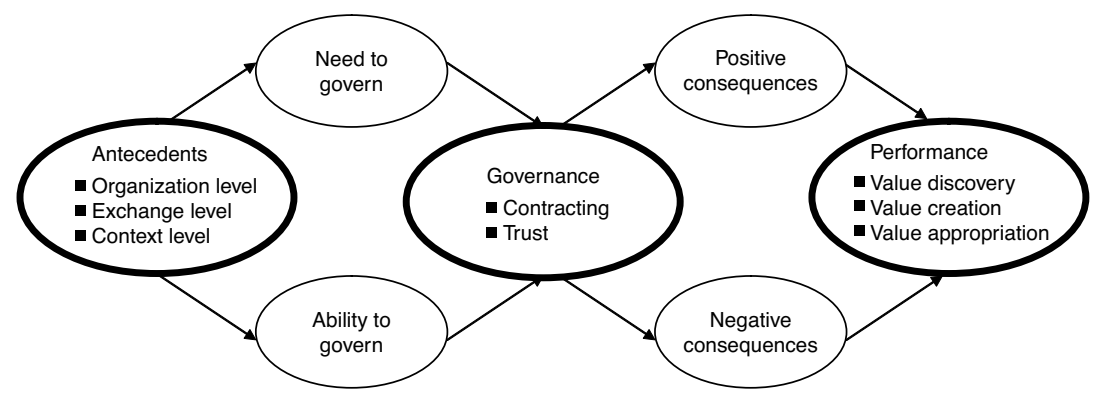

Figure 1.6 Integrative research framework on the role of contracts and trust

\section{RESEARCH THEMES AND QUESTIONS}

Based on the discussion thus far and the research framework presented in Figure 1.6, six research themes were identified that deserve further inquiry. I selected these themes because each of them promises to extend the antecedents-governance-performance model dominating the literature, and because they function as arenas for joining two or more theories, disciplinary fields or perspectives on the role of contracting and trust in interorganizational relations. By doing so, I capitalize on the remark of Oliver and Ebers (1998: 573) that 'there might be a greater opportunity for fruitful cross-disciplinary and cross-perspective dialogue than is often realized' in interorganizational research. I also embrace Kogut's (1988) idea that attempts to melt different theories should be encouraged as they facilitate the development of richer, more insightful explanations for interorganizational phenomena. At the same time, I cherish existing perspectives on alliance governance to a certain extent by accepting the antecedent-governance-performance model as a basis for my work. Starting from such a framework facilitates theoretical progress, as it allows us to start from a coherent knowledge foundation (Bell et al., 2006). By investigating the research questions connected to each of the six themes, I seek to develop new insights and unite apparently disparate research contributions, while preventing research on governance issues in interorganizational relationships from degenerating into a chorus of dissonant voices.

More specifically, the purpose of this study is twofold. First, I seek to develop a more integrative and comprehensive perspective on the role of contracting and trust in interorganizational relationships than is currently envisaged in the literature. I complement the generic antecedents-governanceperformance framework on interorganizational governance that dominates 
the literature, with insights grounded in a variety of theoretical perspectives and backgrounds (e.g. dialectics; sensemaking; mindfulness; law; psychology). By doing so, I answer calls for integrative theory development in a chaotic research field (e.g. see Faems et al., 2007; Koza and Lewin, 1998; Osborn and Hagedoorn, 1997). This should allow researchers and practitioners to better define the governance issues with which they are struggling, and it should assist them in positioning these issues in a broader perspective. Second, I purport to close the gap between theories of what people do and observations of their actual behaviour (Jarzabkowski, 2004). This hiatus emerges because theoretical developments on interorganizational governance are highly fragmented, predicting behaviour on the basis of isolated sets of arguments, disconnected from the versatile nature of actual experience. I address this issue by viewing the role of contracting and trust in interorganizational relationships from different angles, and by highlighting their multifaceted nature and intricate relationships.

The six research themes all build on the generic approach to the research problem presented in the literature, but they also stipulate complementary explanations as to the role of contracting and trust in interorganizational relationships. Each of them focuses on a peculiar part of the research problem, as visualized in Figure 1.6. The order in which the themes are discussed is far from arbitrary. I have deliberately chosen to start with a discussion on several firm and exchange characteristics that are generally acknowledged to influence the complexity, detail or specificity of contracts in interorganizational relationships. The first theme thereby addresses when and to what degree contracting is likely to occur. Theme two subsequently elaborates on the multifarious relationships between contracting and trust, whereas theme three emphasizes the functions of negotiation and contracting in an attempt to reveal why contracting takes place. Building on this, theme four explores how the development and application of formal contracts, rules and procedures influences interorganizational performance. If the locations of these first four research themes were highlighted in Figure 1.6, one would realize that theme one is situated on the left, and that we move further to the right with themes two, three and four. Theme five further qualifies the generic antecedents-governance-performance framework by showing that standardization, an attribute of negotiation and contracting processes, may moderate the relationships captured in this framework. Finally, theme six challenges us to look beyond negotiation and contracting practices, showing that they are intricately related to other governance forms and mechanisms, such as partner selection and advance payments.

As has been memorized before, the common denominator of the six research themes consists of their focus on intersections. The first theme, for 
example, confronts theories that are primarily concerned with the need to contract with theories that focus on the ability to contract. In the second theme, I juxtapose different notions on the relationships between contracting and trust. In theme three, I explore a range of theories attributing distinct virtues or functions to contracting. Theme four, which is labelled 'duality and dialectic tensions', reconciles arguments on the functions and dysfunctions of formalization, illustrating how managers may cope with their coexistence. Theme five discusses contract standardization and unites research on standardization stemming from the contracting and law literatures with studies on mindfulness deriving from cognitive psychology and inquiries into interorganizational cooperation conducted by management scholars. Finally, theme six capitalizes on contributions from various research streams to scrutinize contracting's relationships with other governance mechanisms. Throughout the book, I thus combine different theories, disciplinary fields and perspectives on the role of contracting and trust in interorganizational relationships, so as to subvert 'the provincialism that comes with paradigm confinement' (Gioia and Pitre, 1990: 588) and arrive at a more refined and comprehensive view on their role in interorganizational relationships.

\section{Theme One: Need versus Ability to Contract}

In theme one, I deviate from the antecedents-governance-performance framework by elaborating on the tensions that arise between the need and the ability to contract inputs, behaviour and outcomes. In this study, the 'need to contract' denotes the fact that contracts are requisite, desirable or useful. The 'ability to contract', instead, concerns one's capacity, competence or position to write a contract. Briefly stated, I posit that existing studies either tend to discuss the influence of antecedents on the need, or on the ability to contract (see Carson et al., 2006; Gerwin, 2004; Kirsch, 1997). In this respect, Carson et al. (2006) suggest that the main part of the literature has paid attention to factors which are presumed to increase the need for formal governance, such as asset-specificity, whereas factors representing the ability to govern relationships, such as measurement difficulty or monitoring problems, have received far less attention (see also David and Han, 2004).

I take this argument further by proposing that antecedents of contracting as advanced by transaction cost economists (e.g. Williamson, 1985, 1991), researchers on prior cooperation (Gulati, 1995; Uzzi, 1997), and researchers examining dynamic capabilities (Gulati and Singh, 1998) bring about conflicting forces. In light of these theories, I expect that assetspecificity, exchange complexity, the absence of prior cooperation and 
small organizational sizes aggravate a focal actor's perceived need to contract, while concurrently decreasing its ability to do so. In theme one, I therefore investigate the concurrent effects of such antecedents on the complexity of contracts. This promises to shed light on several contradictory findings emerging from the literature. An example concerns prior cooperation, which is believed to act as a substitute for formal governance, because it reduces the need for safeguards (Das and Teng, 2001; Dyer and Singh, 1998; Gulati, 1995; Inkpen and Currall, 2004). At the same time, however, prior cooperation may also act as a complement to formal governance, because it raises the ability to write more detailed, complex and specific contracts (Mayer and Argyres, 2004; Mellewigt et al., 2007; Poppo and Zenger, 2002). To illuminate such apparent contradictions, I investigate to what extent relationships between different antecedents - on both organization and exchange levels - have opposite effects on the ability and the need to contract. Moreover, I explore how organizations deal with the resulting tensions.

\section{Theme Two: Coevolution of Contracting and Trust}

In theme two, I assert that, despite the fact that 'there is a basic question concerning the role of formal versus informal approaches to the management of' interorganizational relationships (Heckman, 1999: 142), most studies on contracting in interorganizational relationships pay insufficient attention to its relationship with relational governance, in particular trust. Empirical results, however, 'suggest a need to explore more carefully and predict more cautiously the relationship between formal contracts and relational governance' (Poppo and Zenger, 2002: 721). This chimes with the observation that the relationship between trust and control remains far from clear (Maguire et al., 2001; Sydow and Windeler, 2003) and that much theoretical input is still needed to understand how trust and formal contracts work as governance mechanisms (Bachmann, 2001). More specifically, researchers have noted that little attention has been paid to the evolution of both phenomena in cooperative relationships (De Wever et al., 2005; Inkpen and Curall, 2004; for notable exceptions, see Ferrin et al., 2005; Klein Woolthuis et al., 2005; Serva et al., 2005). As a result, practitioners are frequently confronted with conflicting recommendations (see Huxham and Beech, 2003) and academics are left with unclear perspectives on the evolution of contracting and trust in interorganizational relationships. In the second theme, I therefore investigate how contracting and trust evolve in interorganizational relationships, highlighting the salience of and the interplay between both governance forms in interorganizational relationships. 


\section{Theme Three: Functions of Negotiation and Contracting}

Theme three is born out of the observation that most studies on contracting and other forms of formal interorganizational governance tend to focus on aspects of coordination, control and, to a lesser extent, legitimacy (see for instance Dacin et al., 2007; Gulati and Singh, 1998; Kale et al., 2001; Madhok, 2002; Meyer and Rowan, 1977; Salbu, 1997). Mainstream theories generally pass over the fact that contracts and the negotiation and contracting processes from which they emerge may have other functions (some notable exceptions are Ariño and Ring, 2004; Kaghan and Lounsbury, 2006; Lindenberg, 2003). Nevertheless, several authors suggest that alternative explanations and novel understandings of formal organizational structures and practices have become imperative (see Table 1.3). Meyer and Rowan (1977), for example, note that control and coordination are not the only functions of formal governance. In a similar vein, Hatch (1999) argues that changes in business environments cause traditional understandings of organizational structure to break down, thereby implicitly calling for alternative views on the functioning of formal governance mechanisms in modern society. Relatedly, Foss (2001: 4) posits that there is still little

\section{Table 1.3 Need for alternative explanations of formal structures}

\begin{tabular}{|c|c|}
\hline $\begin{array}{l}\text { Meyer and } \\
\text { Rowan } \\
(1977: 343)\end{array}$ & $\begin{array}{l}\text { 'Formal organizations are endemic in modern societies. There is } \\
\text { need for an explanation of their rise that is partially free from the } \\
\text { assumption that, in practice, formal structures actually coordinate } \\
\text { and control work' }\end{array}$ \\
\hline $\begin{array}{l}\text { Hatch } \\
(1999: 75)\end{array}$ & $\begin{array}{l}\text { 'As business becomes more adaptable and flexible in response to } \\
\text { shifting demands and opportunities in their globalizing markets, } \\
\text { traditional understandings of organizational structure are } \\
\text { breaking down' }\end{array}$ \\
\hline $\begin{array}{l}\text { Simons } \\
(1990: 142)\end{array}$ & $\begin{array}{l}\text { 'Management theorists must strive to understand better the } \\
\text { dynamic relationship between strategy and management control } \\
\text { processes. This means [. . . opening up the meaning of } \\
\text { management control to a broader notion ...' }\end{array}$ \\
\hline $\begin{array}{l}\text { Foss } \\
(2001: 4)\end{array}$ & $\begin{array}{l}\text { 'There is still little understanding of how formal control impacts } \\
\text { processes of knowledge sharing (transfer), integration, and } \\
\text { creation' }\end{array}$ \\
\hline $\begin{array}{l}\text { Klein } \\
\text { Woolthuis } \\
\text { et al. } \\
\text { (2005: } 834)\end{array}$ & $\begin{array}{l}\text { 'The general conceptualization of contracts as unidimensional } \\
\text { legal safeguarding instruments is wrong. Our cases show that } \\
\text { contracts may have different functions, which can also be social in } \\
\text { nature' }\end{array}$ \\
\hline
\end{tabular}


understanding of how formal control influences processes related to the sharing, integration and creation of knowledge. Klein Woolthuis et al. (2005: 834) add that contracts may have many functions beyond control. Finally, Simons (1990) concludes that theorists have to open up the meaning of management control to a broader notion. Consistent with the work of other authors (e.g. Kaghan and Lounsbury, 2006; Klein Woolthuis et al., 2005), Simons stresses that formal control systems may be deployed for multiple reasons and purposes, and that they may have a multitude of functions and dysfunctions.

These arguments elicit the question as to whether contracts serve functions beyond coordination, control and legitimacy. They call for research on the interrelationships between contracts and contracting processes, the functions that can be attributed to contracting, and its performance consequences (see Faems et al., 2007; Luo, 2002; Madhok, 2002). By delving into these issues, theme three complements views on contracting as being a means to coordinate, control or legitimize interorganizational activities and outcomes with an alternative perspective viewing it as a 'means to give, make, demand and break sense'. This helps to explain why contracts are encountered in situations where, regarded from existing perspectives, one would not expect them. It also clarifies how contracting might assist partners in solving problems of understanding, transferring pre-existing understandings and co-creating novel understandings so as to discover, create and appropriate value.

\section{Theme Four: Duality and Dialectic Tensions}

Theme four deviates from the mainstream literature by explicitly considering a particular duality inherent in formal contracts, rules and procedures (see Das and Teng, 1998). Earlier studies (e.g. Mintzberg, 1994; Luo, 2002; Williamson, 1985) have recognized that formalities may have functions or 'observed consequences of social patterns that change existing conditions in the direction of socially valued objectives', as well as dysfunctions: 'observed consequences of social patterns that change existing conditions in the direction opposite to socially valued objectives, or consequences that interfere with the attainment of valued objectives' (Blau, 1955: 11). However, they generally suggest that managers have to match these formalities with organization- and exchange-level characteristics in such a way that transaction costs are minimized (Williamson, 1985, 1991) and transaction value is maximized (Foss and Foss, 2005; Ghosh and John, 1999; Madhok, 2002). These inquiries presume that managers are mainly preoccupied with assessing the 'right' degree of formalization, in light of a bunch of organization and exchange characteristics. 
However, these studies offer little guidance on how managers can cope with the tensions arising from the coexistence of formalization's functions and dysfunctions. These tensions cannot always be solved by spatial or temporal separation (Ring and Van de Ven, 1989) and instead have to be managed (Huxham and Beech, 2003). Likewise, I draw theorizing away from generic perspectives in which formalization is determined by organization or exchange characteristics. More specifically, I shift the attention towards a view leaving more room for managerial influence and the management of tensions deriving from coexisting positive and negative consequences of formalization (see Das and Teng, 2000; De Rond, 2003; De Rond and Bouchikhi, 2004). In this way, I illuminate the trade-offs that managers face when ascertaining the most appropriate degree of formalization for a particular relationship. Moreover, I show how managers may cope with and capitalize on these tensions, by analysing a case study of an alliance between two multinationals.

\section{Theme Five: Standardized Contracting Practices}

Theme five extends the generic antecedent-governance-performance framework with an inquiry into an important attribute of negotiation and contracting processes. It offers an arena for discussing how the common practice of using standard contracts and standardized procedures for negotiating and contracting, provisionally defined as established contractual methods that are followed routinely (Cohen and Bacdayan, 1994) and which are created and refined over multiple cycles of exchange (Subramani and Venkatraman, 2003), influences the role of contracting in interorganizational relationships. Although standard contracts and standard procedures for negotiating and contracting are omnipresent (Korobkin, 2003), generic perspectives on the role of contracting in interorganizational relationships do not yet incorporate the influence of standardization. Apart from some incidental research in law schools (e.g. Epstein, 1999; Goetz and Scott, 1985; Kahan and Klausner, 1996, 1997; Korobkin, 2003), hardly any inquiries are undertaken on this subject. In theme five, I address this imbalance between research and practice. I first explain why managers of interorganizational relationships deploy standard contracts and standard procedures for negotiation and contracting. Subsequently, I discuss the disadvantages related to the standardization of negotiation and contracting practices. Most notably, I exploit the assumption that standardization of contracting practices may reduce the degree of mindfulness with which contracts are negotiated and formulated (see Langer, 1989; Ryle, 1949). The results of this theme may serve as a basis for researchers and practitioners to decide whether and when standardization is appropriate. 


\section{Theme Six: Governance Trajectories}

Finally, in theme six, labelled 'governance trajectories', I signal that empirical inquiries following the generic antecedent-governance-performance framework tend to be rather static, concentrating on only one or a few governance modes in isolation (Geringer and Hébert, 1989; Kirsch, 1997). ${ }^{15}$ This is at odds with observations that governance mechanisms are strongly interconnected, that multiple governance mechanisms may have their bearing on interorganizational performance and that managers have various governance mechanisms at their disposal for managing interorganizational relationships. Reuer (1999), for instance, contends that potential value creation in interorganizational relationships involves not only appropriate partner selection, but also the adoption of specific interorganizational designs. Moreover, Klein (2002: 62) notes that increased contractual specification involves rent-dissipating search and negotiation costs'. Similarly, research on the relationship between formal and relational governance mechanisms (see Gulati, 1995; Luo, 2002; Poppo and Zenger, 2002) gives testimony to the existence of highly intricate and dynamic relationships between different governance mechanisms.

Anderson and Dekker (2005) therefore suggest that an important direction for future research involves investigating larger sets of governance mechanisms simultaneously. I therefore establish the concept of governance trajectories, which comprise sequences of interrelated decisions that are made to control, direct or influence the actions and conduct of participants during successive stages of the life cycle of interorganizational relationships. By examining how a number of organization-level and exchange-level factors impinge on various governance choices, and by demonstrating how these governance choices relate to each other, I illuminate the fact that interorganizational management comprises a series of governance decisions. My results indicate that researchers and managers should view interorganizational governance as a dynamic process rather than a static series of decisions.

\section{SCOPE OF THE STUDY}

The principal factor used to delineate the scope of this study pertains to the forms by which economic activities can be organized (see step one in Figure 1.7). The choice for either of these governance forms is frequently labelled in terms of the 'make-buy-or-ally' decision. Williamson (1991) refers to this as first-order economizing, that is, getting the governance mode right. The most commonly used basis for this choice concerns a 


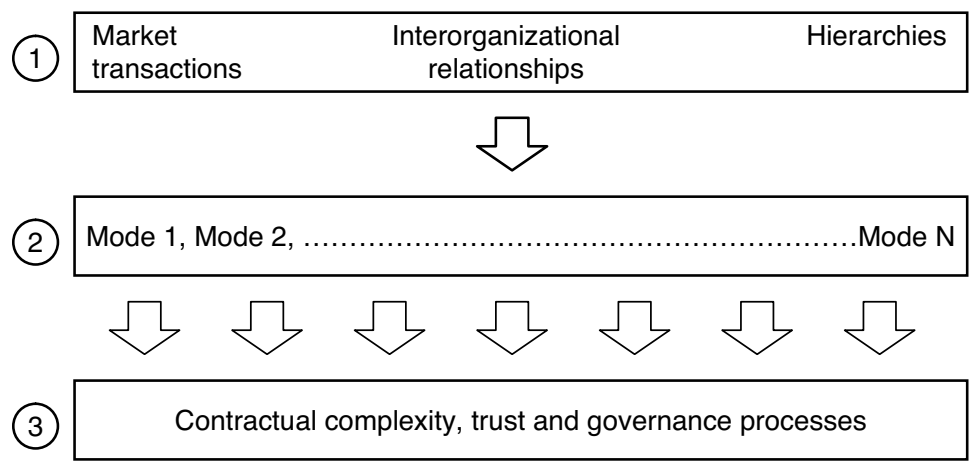

\section{Figure 1.7 The organization of economic activity}

comparative assessment of transaction cost across governance forms (Williamson, 1985). However, others have suggested alternative assessments of discriminating alignment. Hsieh et al. (2007) and Nickerson and Zenger (2004), for example, suggest that the complexity of a problem has to be aligned with the governance form chosen. In this case, problems with low levels of interaction between knowledge sets tend to be organized by the market, problems requiring moderate interaction between knowledge sets tend to be organized by authority-based hierarchy, and problems demanding high levels of interaction among knowledge sets tend to be organized by consensus-based hierarchies.

I do not focus on such a 'make-buy-or-ally' decision, as 'perhaps the type of governance mode does not matter so much [compared to] as what actually goes on within a mode' (Carson et al., 2006: 1072). The organization of activities within different governance modes may, for example, show strong commonalities. Some collaborating firms, for example, gain 'the advantages of vertical integration, without assuming the risks or rigidity of ownership', a situation which is described as vertical quasi-integration (Blois, 1972: 253). Such a situation may occur when prospects of future gains and the degree of interdependence between partners, deriving from such factors as relation-specific investments, a limited number of alternatives, the need for highly specialized knowledge and qualitative coordination, and time compression diseconomies to internalization, render it difficult for firms to maintain managerial independence from their partners (Blois, 1972; Richardson, 1972). Similarly, different governance modes may involve similar governance mechanisms and processes (e.g. negotiation and contracting), rendering inquiries into the latter applicable across a larger number of situations (Thatcher, 2004). Moreover, '[a]rguments designed to prove the inevitability of this or that particular form of organization are 
hard to reconcile [. . .] with the differences that exist within each of these' (Richardson, 1972: 896). Finally, governance modes may be complementary, rendering comparative assessments of the appropriateness of governance modes less valuable (Grandori, 1997, 2007). I therefore exclude pure market-based transactions and vertically integrated forms of organization from the discussion.

This means that I restrict the study to the role of contracting and trust within interorganizational relationships, such as joint ventures, strategic alliances and buyer-supplier, outsourcing and offshoring relationships. Such relationships become pertinent when 'vertical integration is neither economical nor technically feasible and arms-length transactions cannot meet demands for customization' (Anderson and Dekker, 2005: 1737). As Richardson (1972: 892) stated:

They exist because of the need to co-ordinate closely complementary but dissimilar activities. This coordination cannot be left entirely to direction within firms because the activities are dissimilar, and cannot be left to market forces in that it requires not the balancing of the aggregate supply of something with the aggregate demand for it but rather the matching, both qualitative and quantitative, of individual enterprise plans.

Richardson (1972: 885) offers the example of plumbing work on a building contract, noting that:

[it] may be subcontracted on the basis of competitive tenders for the individual job. Frequently, however, the relationship between the parties acquires a degree of stability, which is important for two reasons. It is necessary, in the first place, to induce sub-contractors to assume the risks inherent in a rather narrow specialization in skills and equipment; and, secondly, it permits continuing cooperation between those concerned in the development of specifications processes and designs. [That is, it allows for qualitative coordination].

Partners in these relationships can exert only limited degrees of control (Gomes-Casseres, 1996) and they 'seem to accept some degree of obligation - and therefore give some degree of assurance - with respect to their future conduct' (Richardson, 1972: 886). Collaborating organizations thus lose the freedom to act independently (Van de Ven and Walker, 1984) and they have to work from a position that combines features of organizations and markets (Stinchcombe, 1985). Although interorganizational relationships remain separate entities, they entail higher degrees of interdependence than market transactions, making the outcome for any player in an exchange 'fundamentally entwined with the actions of and outcomes for other players' (Child and McGrath, 2001: 1139). Such relationships not only entail interdependency, they also inhabit collective strengths aimed at 
value creation and inter-partner conflicts deriving from, amongst others, desires to appropriate part of this value (Das and Teng, 2002).

The second step in Figure 1.7, which comprises the selection of a particular collaborative form or cooperative mode, is not central to this study either. The key issue here is no longer whether cooperation should take place, but rather in which mode or form a particular relationship should be organized (Heide, 1994; Sampson, 2007). Possibilities include, amongst others, buyer-supplier relationships, outsourcing agreements, joint research projects, shared new product development, common distribution agreements, R\&D alliances, joint ventures and franchising (Grant and Baden-Fuller, 2004). An inquiry into $463 \mathrm{R} \& \mathrm{D}$ alliances in the telecommunications equipment industry by Sampson (2007) serves as an example here. Sampson's analysis indicated that, in cases of high technological diversity among partners, choosing an equity joint venture instead of a contractual alliance form is more likely to preserve incentives and mechanisms to share information. However, Sampson (2007: 384) also notes that "variance clearly exists within each of these broad groupings, and many different mechanisms for dealing with the coordination challenges inherent in R\&D collaborations exist within each of these organizational forms'. She hints at the third step in Figure 1.7 here, suggesting that, after a collaborative mode or form is chosen, partners engage in governance processes such as selecting partners, negotiation and developing contracts and establishing trust to varying degrees (Nooteboom, 1999). Williamson (1991) refers to this as second-order economizing - i.e. executing adjustments within a particular governance mode. The processes and outcomes involved here constitute the focal phenomena examined in this book. They concern the management and implementation of interorganizational relationships, something which has received little attention compared to the decisions depicted in stages one and two of Figure 1.7 (Reuer and Ariño, 2007; Sobrero and Roberts, 2002).

A second demarcation of scope relates to the literature that is being used. Following Anderson and Dekker (2005), throughout the book reference is made to theoretical and empirical contributions on governance at both the intra- and the interorganizational level. I consider this to be appropriate, since interactions within and between organizations show several fundamental similarities (Gittell and Weiss, 2004; Lorenzoni and Lipparini, 1999) and, as others have noted, research on the management of partnerships 'can and perhaps should draw on many conventional managerial nostrums developed with hierarchical organizations in mind' (Thatcher, 2004: 121). Adopting such a stance is further supported by findings from Gittell and Weiss (2004) and Håkansson and Lind (2004), indicating that various structuring practices commonly adopted within organizations are perfectly 
adequate for coordination in interorganizational relationships. In their study of healthcare organizations, for example, Gittell and Weiss (2004) found that many of the same mechanisms that have been found to be effective in linking units within organizations are also effective for linking activities across organizations. Others have argued that collaborative relationships also resemble organizations in that they are frequently characterized by their own distinctive organizational systems, rules, routines and norms (Grandori and Soda, 1995; Thatcher, 2004). In line with these observations, Grandori (2000: 6) even proposes that 'a unitary and general theory of governance - encompassing both [. . . internal and external organization - is possible'. As I believe that some partnerships have more in common with conventional organizations than much of the literature suggests, I refer to literature on intraorganizational governance wherever it may be helpful in developing our understanding of the role of contracting and trust in interorganizational relationships.

Nonetheless, I recognize that one cannot completely equate interorganizational structures and structuring practices with their organizational counterparts. There may be important differences between organizing activities in organizations and organizing them in interorganizational relationships, which influence the role of contracting and trust in each. One of the differences playing a role is that organizations contain 'more forces against change'. They are characterized by ingrained interests, established ways of doing things, loyalties among employees, and so on (Gomes-Casseres, 1996: 85). This may result in situations in which formalities are met with less opposition when applied in interorganizational relationships as compared to organizations. Besides, contracts tend to be almost imperative for interorganizational cooperation, because a 'tiebreaking authority higher up, and a common ownership interest by which to judge which side provides the greatest contribution' are generally lacking (Gomes-Casseres, 1996: 92). In this case, they have few other preexisting mechanisms for control and coordination at their disposal (Kirsch, 1997). Moreover, participants in interorganizational relationships are more likely to face higher degrees of uncertainty and equivocality compared to their counterparts within organizations. They lack stable and time-tested governance structures, but they also face discontinuities in terms of experience, culture, technology and organizational practices. The absence of generic understandings further complicates sensemaking, and it is likely to influence the structures and structuring practices adopted by partners (Clegg et al., 2002a). This is reinforced by the fact that interorganizational relationships tend to occur less frequently and are more heterogeneous than other organizational activities (Reuer and Zollo, 2005). 
In contrast, the zone of acceptance of authority, defined as the willingness to accept decisions from others (Simon, 1997: 185), is probably larger for departments cooperating within an organization compared to parties in interorganizational relationships, as the latter can opt out more easily. This may reduce participants' willingness to conform to formalities and formal governance solutions. In addition, compared to internal organizational units, interorganizational relationships tend to have a much narrower mandate (Reuer and Zollo, 2005), something which reduces the need for formal governance. Finally, contracts comprise only one of the many means by which control can be achieved in interorganizational relationships (see Klein Woolthuis et al., 2005). Participants may use other governance mechanisms, which have little significance when activities are organized within organizations, such as efforts invested in partner selection, or equity exchange. We should keep these differences between organizing activities within organizations and organizing activities in collaborative relationships in mind when discussing the role of contracting and trust in interorganizational relationships.

\section{METHODOLOGICAL CONSIDERATIONS}

Karl Weick (1995: 35) once asked, 'If people have multiple identities and deal with multiple realities, why should we expect them to be ontological purists?' He stated that this would only limit their capability for sense making. Stated differently, working from a single ontological paradigm frequently 'produces a potentially valuable, but narrow view, incapable of exposing the multi-facetted nature of organizational reality' (Lewis and Kelemen, 2002: 268). At the same time, however, 'multiparadigm researchers live in a glasshouse open to attack' from researchers tied to single paradigms (Lewis and Kelemen, 2002: 259). In the remainder of the book, I nonetheless adopt a pluralistic approach. This is likely to lead to the most comprehensive, nuanced and accurate picture of the role of contracting and trust in interorganizational relationships. It reduces the risk that only one aspect of the phenomenon under study is being highlighted (Knudsen, 2003; Mintzberg and Lampel, 1999) and it can provoke discourse and inquiry across a number of paradigms (Lewis and Kelemen, 2002), which may eventually offer a more reliable guide to action than inquiries based on single paradigms (Volberda and Lewin, 2003). By starting from a variety of ontological stances and by using multiple methodological and conceptual lenses, it becomes less likely that erroneous conclusions are drawn, as has been vigorously illustrated in Allison's (1971) seminal work, Essence of decision, in which the Cuban missile crisis was 
analysed in terms of three alternative frames of reference. Consistent with Yin (1994), Gioia and Pitre (1990) and Azevedo (2002), different methods, accompanied by different methodological presuppositions, are being used to answer different kinds of research questions, to highlight different facets of the phenomenon, and to make different sorts of information accessible. This should provide a richer understanding of the role of contracting and trust in interorganizational relationships than any one approach on its own (see Van de Ven and Poole, 2005).

Some of the research questions posed in the book need to be explored by means of an inductive approach. Or, as Klein (2002: 69) puts it, to increase our understanding of contracts and other formalities 'it is [sometimes] necessary to get one's hands dirty and discover how particular contracts actually work in practice'. This approach conforms to Ronald Coase's (1992) plea for economists to develop a much more detailed understanding of the actual process of contracting between companies in a 'real-world setting'. Case studies are needed because contracts and other acts of formalization 'do not constitute a closed universe' (Brousseau and Glachant, 2002: 23); they are embedded in contexts that influence their functioning. Furthermore, case studies 'allow an investigation to retain the holistic and meaningful components of real-life events - such as [. . .] organizational and managerial processes' (Yin, 1994: 3). They enable us to get a feeling of which variables are involved, how they could be measured, and how relationships between the variables might be constructed (Eisenhardt, 1989a; Yin, 1994). When investigating the role of contracting and trust, case studies become particularly useful when organizational processes are involved which do not lend themselves easily to quantitative measurements (Siggelkow, 2007; Strauss and Corbin, 1998), ${ }^{16}$ and when history and context need to be incorporated (Pettigrew, 1990).

Moreover, adopting the case study approach in research on contracting aligns with Simon's (1997) advice on obtaining insights into the structure and functioning of organizations. He suggests that such insights may be gained by 'analyzing the manner in which the decisions and behaviour' of employees are influenced (Simon, 1997: 2). It also conforms to Siggelkow's (2007: 22) observation that case studies help in 'getting closer to constructs and being able to illustrate causal relationships more directly'. In doing so, the case study method meets the critique of existing research concerning the notable paucity of studies penetrating the operational level of interorganizational relationships (Marchington and Vincent, 2004; Parkhe, 1993b). It also connects to the growing attention for post-formation dynamics and developmental processes in interorganizational relationships (Ariño and de la Torre, 1998; Doz, 1996; Doz and Hamel, 1998; Ring and Van de Ven, 1994; Reuer et al., 2002; De Rond, 2003). Finally, it coincides 
with academic inquiries into the 'human' or 'process' side of contracting and, more generally, structuring activities and outcomes (Marginson and Ogden, 2005) enabling the development of perspectives on contracting that are 'adequate at the analytical levels of meaning and of causality' (see Ranson et al., 1980: 4). This has led to the use of the case study method in theme four, which focuses on a so-called 'how-question' (Yin, 1994), namely: how do managers of interorganizational relationships cope with the tensions arising from the coexistence of functions and dysfunctions of using contracts, rules and procedures?

The case study that I discuss concerns a strategic alliance between a large European-based retailer (STEADY) and a global financial services organization (QUICK) aimed at the integration of financial services in a retail context. I selected it for this study, as it fulfils three practical and theoretical conditions. First, both companies offered me unique access to their documents and participants in the relationship. Second, both organizations are large in size, something which is often linked to higher levels of formalization (Zeffane, 1989), and which enlarges the likelihood that formalization would be an issue in the alliance. Third, the alliance under study required innovative activities from both organizations, while simultaneously posing high demands for formalization, arising from the legitimacy, accountability and control characterizing financial services (see Vermeulen, 2001). This setting offered fertile ground for tensions arising from the coexistence of formalization's functions and dysfunctions, which is central to theme four.

In contrast to the case study method, the survey method is used to attain parsimony and external validity (Eisenhardt, 2000). It is a method that is helpful in illuminating the prevalence and incidence of certain phenomena (Yin, 1994). More specifically, surveys are utilized to establish generalizable relationships between contracting, trust, antecedents, interorganizational performance, moderators, mediators and other governance variables. Investigating these relationships requires large samples of interorganizational cooperative endeavours, which reduce the risk that findings are the result of highly context-specific or idiosyncratic confounding elements. Where the case study sacrifices breadth for depth (Gill and Butler, 2003), the survey offers some compensation, enabling us to draw more generalizable conclusions. The data used to answer the research questions posed in themes one, five and six are obtained from a dataset called The External Management of Automation [MAT95] (Batenburg and Raub, 1995). ${ }^{17}$ This dataset captures data on 971 buyer-supplier relationships in which smalland medium-sized buyers have purchased IT solutions from vendors. The sample includes bilateral contracts: contracts which are in some substantial sense incomplete (Gomes-Casseres, 1996; Grossman and Hart, 1986), and which involve promises that possibly have their bearing on the partners 
during a longer period of time (Ring, 2002), making at least one of the organizations in the relationship dependent on the other (Das and Teng, 2000). Although, at first sight, these relationships might resemble market transactions, they constitute interorganizational relationships as they entail the delivery of products or services over longer periods of time. This means that interorganizational participants have to interact through series of stages in which they select their partners, refine specifications of requirements and deliver goods or services (Bennett and Robson, 2004).

I have selected this type of relationship as the object of analysis, for several reasons. First, buyer-supplier relationships are becoming more important, thanks to increased competition and a higher pace of innovation, which calls for close cooperation between buyers and suppliers (Noorderhaven et al., 1998). Second, survey data on buyer-supplier relationships could be obtained on a larger scale than data on other types of relationships (response rates for surveys under alliance managers, for example, generally approximate 10 per cent). Third, transactions involving the purchase of IT solutions offer an appropriate context to test several of the hypotheses that are developed in later chapters, because such relationships generally entail numerous control and coordination problems. Buyers face various risks, stemming, among other factors, from the difficulty of remaining up-to-date with respect to technological developments and from suppliers that behave opportunistically, painting too rosy a picture of their technology, implementation costs or operational costs (Rooks, 2002; Rooks et al., 2006). Besides, buyers in such relationships regularly face low supplier capability, poor supplier performance, loss of control and overdependence (Poppo and Zenger, 2002). Moreover, buyer-supplier relationships are characterized by uncertainty and information-asymmetry between buyers and sellers, which complicate the specification of desired behaviour and outcomes (e.g. Barthélemy, 2001). Accompanied by the relationspecific investments and product customization that are frequently required in such relationships, this ultimately demands the integration and coordination of actions by means of formal contracts and governance processes (Anderson and Dekker, 2005). Appendix A provides more data on the survey.

The approach taken to study contracting and trust can be further classified along the typology of Van de Ven and Poole (2005). These authors distinguish ontological views of 'organization as things' from ontological views of 'organization as processes'. They also discern 'variance' and 'process' epistemologies. This renders a two-by-two matrix of possible research approaches to studying particular organizational phenomena. From an ontological viewpoint, the studies presented in subsequent chapters both cover contracts and trust (i.e. nouns, real entities or 
things) and governance processes (i.e. negotiating and contracting, developing trust). The approach that is taken to explore the role of contracting and trust in interorganizational relationships is therefore necessarily pluralistic in nature (see Van de Ven and Poole, 2005). Moreover, the book builds both on variance methods and on process narratives.

In the chapters entitled Need versus ability to contract, Contract standardization, and Governance trajectories, I attempt to explain lawful regularities, and adopt a rather mechanistic approach to organizational analysis (Child, 1997). ${ }^{18}$ In doing so, I do not presume that these regularities dominate human agency (Voss, 2003), but I assume that they can still be distinguished in spite of the existence of human agency. The research questions posed in the other chapters, instead, demand a research approach that is able to offer insights into individuals' unique interpretations of the phenomenal world, of their attributions of causality to events surrounding them, and of interpretations, social constructions and sense makings of others' behaviours (Chia, 1997). Such an approach entails a process-based ontology, which opens up the possibilities for rethinking 'organization', or in this case governance as a process of 'world-making' (Chia, 1997: 685). In Chia's terms (2003: 136), interorganizational governance could become 'a ceaseless process of reality construction and maintenance that enables us to carve out our otherwise amorphous life-worlds into manageable parts so that we can act purposefully and productively amidst a flood of competing and attention-seeking stimuli'. This draws 'the logic of organizational theorizing away from structured entities, outcomes, and end-states, towards the underlying thought-structuring processes, which produce these outcomes' (Chia, 1997: 703). In theme three, for example, I deviate from the conventional perspectives on contracting by depicting it as a structuring processes (Hatch, 1999), which entails the transformation of thought and meaning in individuals (Chia, 2003). ${ }^{19}$

\section{EMPIRICAL BASIS}

The unit of analysis in this research is the interorganizational relationship. Congruent with this, the empirical basis for the study consists of interorganizational relationships involving at least one services organization, being an IT organization, a financial institution, or a retail organization. The focus on services organizations is born out of the relative silence in previous research on interorganizational relationships including these types of organizations, and the increasing tendency towards external cooperation by such organizations. Recent figures of the OECD, for example, demonstrate that alliances involving services activities absorb a strongly growing 


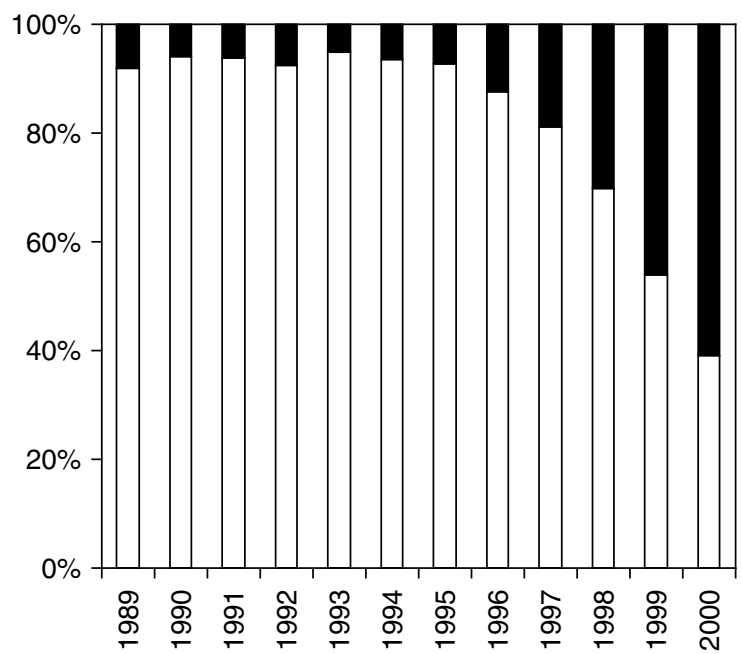

Business services
Manufacturing, marketing, R\&D

Source: Kang and Sakai (2001).

Figure 1.8 Purpose of alliances worldwide

share of total worldwide alliance activity compared to manufacturing, marketing and R\&D activities (Figure 1.8). More specifically, the number of interorganizational cooperative relationships involving services organizations in 2000 was more than five times as high as in 1995 (Kang and Sakai, 2001). In the empirical investigations, I further restrict myself to non-equity relationships, as it is now recognized that interorganizational cooperation increasingly takes place in less hierarchical forms. Although earlier research tended to concentrate on the choice between equity and non-equity forms of cooperation (Grandori and Soda, 1995; Heiman and Nickerson, 2004; Oxley, 1997; Reuer and Ariño, 2003), the relative importance of joint ventures compared to alliances is declining sharply (Figure 1.9). Hagedoorn and Osborn (2002) even ascertain that the percentage of joint ventures in newly established R\&D partnerships declined from 90 per cent in 1970 to less than 10 per cent in 1998.

Although the focus is on interorganizational relationships involving services firms, I refrain from emphasizing only one particular type of relationship. I thus deploy a kind of empirical pluralism, seeking progress 'by applying basically the same set of theoretical principles to a broad class of 


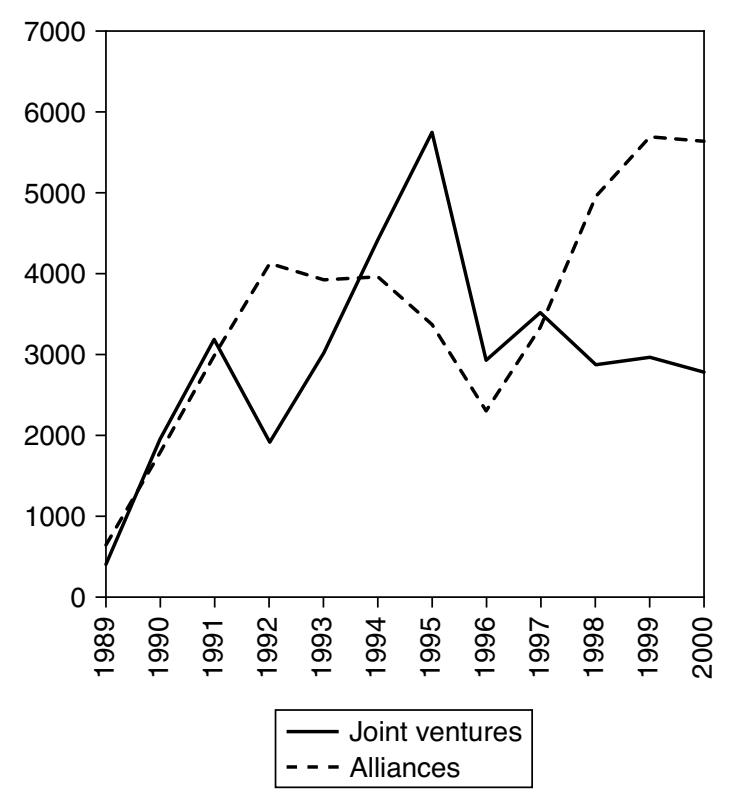

Source: Kang and Sakai (2001).

\section{Figure 1.9 Joint ventures versus alliances}

empirical phenomena' (Buskens et al., 2003a: 5). Such an approach seems to be warranted by the fact that contracting and trust appear to play a role in almost any kind of interorganizational relationship, ranging from licensing agreements to strategic alliances. An indication of the significance of contracts for different types of interorganizational agreements can be derived, for example, from their length (Hill and King, 2004). Table 1.4 presents a basic analysis of the length of 591 licence agreements, 336 sales and marketing agreements, 161 manufacturing and supply agreements, 73 consultancy agreements, 87 R\&D agreements and 137 strategic cooperation agreements (source: onecle.com). A simple word-count for each of the contracts, followed by a sorting procedure in which relationships are ordered according to ascending contract length, is summarized in Figure 1.10.

Descriptive statistics reveal that contract length in this convenience sample ranges between 217 and 75608 words. Mean values differ significantly between different types of relationships, with consultancy agreements having the lowest mean value (2841 words) and strategic cooperation agreements displaying the highest value (11844 words). Large differences in contract length, even within categories of relationships, are consonant with the core assumption that there is considerable variation in 
Table 1.4 Variation in contractual complexity

\begin{tabular}{|c|c|c|c|c|c|c|}
\hline & 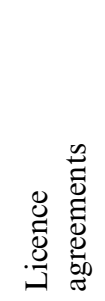 & 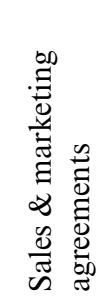 & 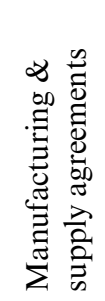 & 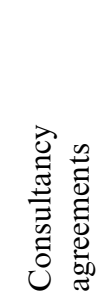 & 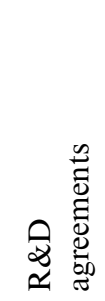 & 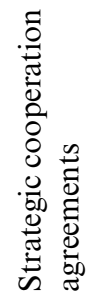 \\
\hline Mean (\# words) & 8729 & 7575 & 8893 & 2841 & 9058 & 11844 \\
\hline Std. deviation & 7480 & 6832 & 9454 & 2438 & 7120 & 12201 \\
\hline Median & 6961 & 5868 & 6927 & 2176 & 6815 & 7097 \\
\hline Minimum & 421 & 127 & 256 & 262 & 217 & 423 \\
\hline Maximum & 65286 & 38168 & 75608 & 14288 & 28865 & 64834 \\
\hline $\mathrm{N}$ & 591 & 336 & 161 & 73 & 87 & 137 \\
\hline
\end{tabular}

Source: Data were obtained from onecle.com and analysed by the author.

the level of detail and complexity of contracts across interorganizational relationships and firms (Park and Ungson, 2001; Argyres et al., 2007). This variation may derive, for instance, from differences in exchange characteristics (Williamson, 1985), but it may also stem from the fact that some organizations are more skilled than other organizations in designing appropriate coordination and control structures (Anderson and Dekker, 2005; Argyres and Mayer, 2007; Mayer and Argyres, 2004). In this respect, Ring (2002: 145) proposes that 'one of the elements that makes some organizations better at forming and sustaining cooperative relationships is that they have a better understanding of the consequences that flow from a need to rely, in part, on contract in the governance of cooperative business relationships'.

\section{OVERVIEW OF THE BOOK}

The purpose of Chapter 1 was to set the stage for a manuscript aimed at developing a series of alternative perspectives and a more integrative view on the role of contracting and trust in interorganizational relationships. Chapter 2 serves as the basis for all other chapters, as it discusses the coordination and control perspectives that have traditionally dominated inquiries into interorganizational governance (providing the antecedents-governance-performance framework with a theoretical basis). In Chapters 3 to 8, 
Licence agreements

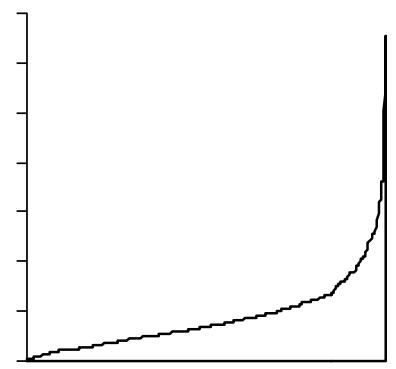

$(N=591, \bar{X}=8729)$

Manufacturing/supply agreements

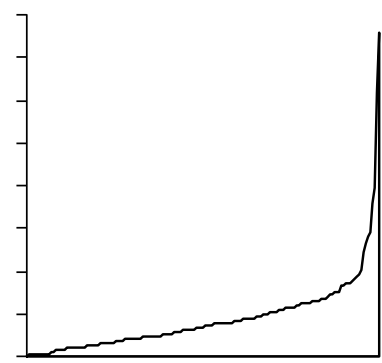

$(\mathrm{N}=161, \overline{\mathrm{X}}=8893)$

$R \& D$ agreements

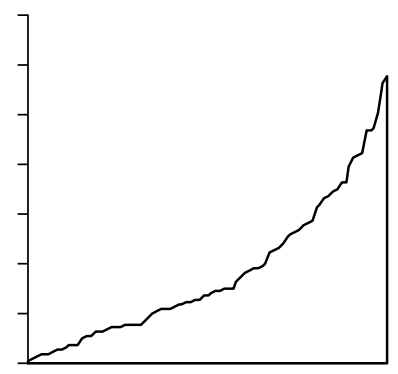

$(\mathrm{N}=87, \bar{X}=9085)$
Sales \& marketing agreements

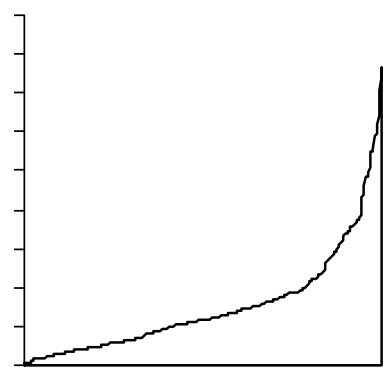

$(N=336, \bar{X}=7575)$

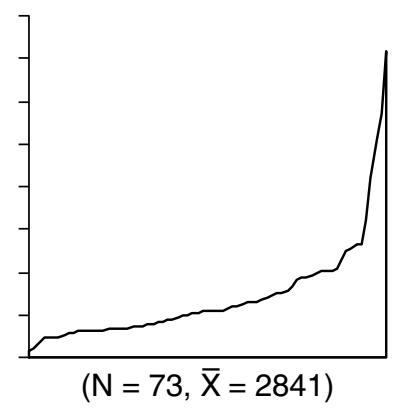

Strategic cooperation agreements

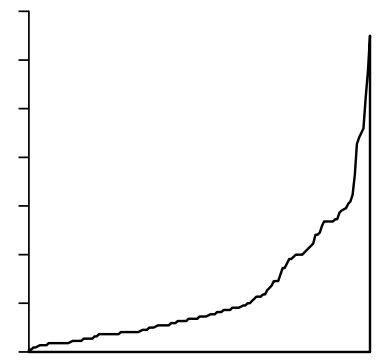

$(\mathrm{N}=137, \overline{\mathrm{X}}=11844)$

Figure 1.10 Distribution of contract length in words for different kinds of agreements 
however, I comply with Osborn and Hagedoorn's (1997) request to abandon singular, clear-cut descriptions of interorganizational cooperation and replace them with more robust, comprehensive, multidimensional views. In these chapters, each of the six research themes identified before are explored in greater detail. The chapters are all written along similar lines, in that they start with a description of the themes' relationship to the research problem and the research framework presented in Figure 1.6. These brief introductions are followed by descriptions of possible enrichments of, and complements to, the generic control and coordination perspectives on the role of contracts in interorganizational relationships. In Chapter 9, I contemplate a synopsis of the main theoretical developments and the key findings emanating from the case study and the survey data. I also highlight the theoretical and practical implications of the study, as well as the limitations of the study and several possibilities for future research.

\section{CONCLUSION}

This chapter served as an introductory guide to a number of studies on the role of contracting and trust in interorganizational relationships. It started with the growing significance of interorganizational cooperation, and then emphasized the need for a better understanding of contracting and trust in collaborative initiatives. In order to address this issue, I devised an integrative research framework and identified six research themes, which complement the coordination and control perspectives and the antecedentgovernance-performance framework that currently dominate research on interorganizational governance. Subsequently, I discussed the scope of the research, its methodological and empirical bases, and the structure of the book. In the following chapter, I provide a comprehensive account of the coordination and control perspectives that currently seem to be most influential on our thinking about formal interorganizational governance.

\section{NOTES}

1. The question of why firms create interorganizational relationships is by now 'standard fare' in the literature (Gomes-Casseres, 1996: 13). The general argument is perhaps best represented by Durkheim, who remarked: 'the hardness of bronze lies neither in the copper, nor in the tin, nor in the lead which have been used to form it, which are all soft and malleable bodies. The hardness arises from the mixing of them' (Durkheim, 1982: 39-40).

2. In this respect, Gomes-Casseres (1996) contends that cooperation is not a natural act for companies. Everything in their competitive environment and in their corporate histories drives them toward win-lose competition and a reliance on internal resources. 
3. Bozeman and Kingsley (1998) explain that project documentation, change requests forms or notes of staff meetings can also serve as contracts, as they protect participants from risks and control their behaviour.

4. On a macroeconomic level, limited enforceability of contracts impairs the efficient allocation of resources. It also results in greater volatility of outputs, and it delays the diffusion of new technologies (Cooley et al., 2004). There are no reasons to believe that similar effects do not apply to interorganizational cooperation. When organizations are not able to guarantee a certain extent of compliance to agreements, potential partners will refrain from initiating relationships altogether, or they are handed over to the whims of their partner, which potentially results in a higher variability of the expected outcomes of relationships.

5. Authority is defined here as 'the power to make decisions which guide the actions of another' (Simon, 1997: 74). This power is 'recognized as so vested, and [. . .] accepted as appropriate not only by the wielder of power, but by those over whom it is wielded and by the other members of the system' (Katz and Kahn, 1966: 203).

6. The threat of retaliation will generally deter non-compliance with agreements. From a control perspective, possibilities for legal enforcement only need to deal with states in which payoffs for deviations from the norm are very high (Eggleston et al., 2000). Friedrich's 'rule of anticipated reactions' seems to be valid here, which suggests that expectations and anticipations govern behaviour (Simon, 1997: 182). Potential disputes, including many that under current rules could be brought to a court, are frequently resolved by avoidance, self-help and the like (Galanter, 1981).

7. The distinction between the formalization of inputs and outcomes, and the formalization of processes is theoretically important but empirically hard to make. Ultimately, formalization is exercised to change behaviours (Kirsch, 1997; Ouchi, 1979). Simon (1997: 39) clarifies that there is no essential difference between a desired outcome and a process, but only a distinction of degree. A process is an activity whose immediate purpose is at a low level in the hierarchy of means and ends, while a desired outcome is a collection of activities whose aim is at a high level in this means-end hierarchy.

8. The resemblance between this distinction and the two kinds of bureaucracy described by Max Weber is striking. Weber wrote about a 'representative' form of bureaucracy, based on rules established by agreement, rules which are technically justified and administered by specially qualified personnel, and to which consent is given voluntarily. However, he also described 'punishment-centred' bureaucracies, which are based on the imposition of rules and on obedience for their own sake (Gouldner, 1954: 24).

9. Enabling types of formalization require flexibility (Adler and Borys, 1996) and openness of all parties to each others' requests to modify prior agreements in case unexpected situations arise (Bello and Gilliland, 1997). Enabling types of formalization also demand involvement from parties to an agreement during the contracting process and managerial encouragement for formulating improvements (Adler and Borys, 1996). After all, people prefer agreed-upon, rather than imposed conditions (Gouldner, 1954: 20).

10. Continuity is more likely to play a role in the development of trust, when prior experience renders it more efficient to do so. This occurs, for example, when parties have conducted relation-specific investments in developing processes and norms that support justice and cooperation during earlier exchanges (Ring and Van de Ven, 1994). In such instances, prior collaboration enables 'continued savings from decreased transaction costs' and it potentially enhances value creation, as parties have learned about the normative routines applying to the relationship, each other's capabilities and objectives, and the kind of behaviour to expect from each other (Poppo et al., 2008: 8).

11. Olk (2002) suggests one such an approach. Building on studies of organizational effectiveness, he organizes different approaches to performance measurement according to different levels of analysis: that of the relationship and that of the partner organizations (see Gray, 2000; Yan and Gray, 1995). Moreover, he distinguishes performance measures according to their purpose or approach. Olk contends that, in an optimization approach, all parties use a single criterion for evaluation. In a strategic interest approach, one goal prevails as well, but a dominant coalition may use several representative 
measures, and goals may change. In a multi-interest approach, there are multiple evaluators of interorganizational performance, which use different and sometimes conflicting criteria. Finally, in a sequential perspective, multiple criteria are used for evaluation, which are assumed to be temporally related (Olk, 2002).

12. Another example concerns performance measures assessing the degree to which strategic interests of cooperating organizations are accomplished. Criticism of these measures centres on the fact that they are perceptual (Olk, 2002), and that objectives may change over time (Gill and Butler, 2003). Besides, such measures are confronted with validity problems, due to a deficiency of common objectives and the coexistence of multiple strategic objectives (De Rond, 2003; Larson, 1992; Yan and Gray, 1995). Moreover, such measures do not take into account spillovers, or the benefits and costs that accrue to one or both of the parties that go beyond the scope of the transaction (Khanna, 1998; Mayer, 2006). The latter has received little attention, despite the fact that spillovers can have significant effects on an organization's competitive position by adding to or devaluing the firm's resources (e.g., knowledge and reputation) (Mayer, 2006).

13. Grandori (2006: 128) further specifies this by stating that 'The flexibility rigidity outcome does not have to do with formalization [per se], but with the degree of detail in the specification of proper behaviour [. . . . Hence, we can have "flexible formalization" - if rules are general and "constitutional" enough - and rigid social governance - if norms are very precept-like and detailed.'

14. Research on relational governance suffers from similar problems. Saparito et al. (2004: 400), for example, claims that 'studies of interfirm trust have focused either on its antecedents or its consequences, but not [on] both.'

15. Studies that do examine multiple governance mechanisms frequently only analyse a few relationships between a limited number of governance mechanisms, such as the relation between formal governance and the selection of familiar partners (e.g., see Gulati, 1995; Poppo and Zenger, 2002) or trust (see Luo, 2002).

16. More specifically, Siggelkow (2007: 22) argues that 'In large-sample work, the distance between conceptual constructs and measurable variables is often rather large [ . . . If the econometrics is done convincingly, the reader may well believe that an empirical relationship has been documented between proxies $\mathrm{E}$ and F. But whether this relationship really reflects the underlying conceptual arguments concerning constructs $\mathrm{A}$ and $\mathrm{B}$ is often quite unclear.'

17. The data set, The External Management of Automation, has been collected as part of the NWO-pioneer programme 'The Management of Matches' (PGS 50-370) and is available from the Steinmetz-Archive (study number P1512). For more details on the datacollection procedure, we refer to Anderson and Dekker (2005), Batenburg (1997), Batenburg et al. (2003), Buskens (2002), Dekker (2003) and Rooks (2002). Several of the items used in the study have been used in other studies (see for instance Rooks et al. (2006) and Dekker (2003)).

18. This approach to research has not remained free of criticism. Piore (1995: 63), for example, notes that 'the basic problem of this methodological stance is its commitment to an individualist ethos and its inability to recognize and accord a legitimate place to organic groups and cohesive social organizations'. Others signal that it leads to the lack of attempts to seek out underlying causes or generative mechanisms of observed phenomena. The most notable criticism of such an approach centres on (1) its conceptualization of agency, (2) its inattentiveness to meaning, and (3) the relations it presumes between structure and agency (Chia, 1997). Considering the first point, researchers adopting this approach presume that the question of what an agent 'does' coincides with his or her 'intentions' (Giddens, 1984). However, the knowledgeability of human actors is always bounded on the one hand by the unconscious, and, on the other hand, by unacknowledged conditions or unintended consequences of action (Giddens, 1984; McKinley and Scherer, 2000; Weick, 1995). The second critical note refers to the fact that it keeps theories and findings of the social sciences wholly separate from the universe of meaning (Giddens, 1984). In doing this, nature becomes 'a dull affair, soundless, scentless, colourless; merely the hurrying of material, endlessly, meaninglessly' (Whitehead, 
1985: 68). Conducting research on structural parameters without considering the intentions that individuals have with these structures and the meaning they give them therefore appears inept (e.g., Weick, 1979). The third point of criticism concerns the relationship between structure and agency. Although it has been argued that structure comprises 'forces that lie outside the control and often the comprehension of placebound actors' (Kumar, 1995: 188), and that structures are frequently 'irreducible to the activities of contemporary agents' (Reed, 1997: 33), structures also exist only when they are socially reproduced and transformed (Barley, 1986). It seems unrealistic to presume that agents do not influence organizational structures.

19. Criticism also applies to this methodological standing. Reed (1997), for example, proposes that a process view on structure - or structuring - leaves us with a conception of organization in which properties of structures that 'can be understood to be relatively independent of the agents whose behaviour is subject to their influence' (Layder, 1990: 23) are pushed aside by the 'analytical fascination with the local, contingent, and indeterminate' (Reed, 1997). He proceeds by stating that 'flat ontologies and miniaturized local orderings construct a seductive vision of our social world in which everything and everybody is constantly in a 'state of becoming' and never in a 'condition of being' (Reed, 1997: 29). To support his arguments, Reed refers to Schumpeter's warning that 'social structures, types, and attitudes are coins that do not readily melt. Once they are formed, they persist, possibly for centuries'. He remarks that this is 'conveniently forgotten in a cacophony of celebrations to the essential flux, fragmentation, and indeterminacy of social reality' (Reed, 1997: 26). 